\title{
Driveline Torsional Analysis and Clutch Damper Optimization for Reducing Gear Rattle
}

\author{
Huwei $W u^{1}$ and Guangqiang $W u^{1,2}$ \\ ${ }^{1}$ College of Automotive Studies, Tongji University, 4800 Cao'an Road, Jiading District, Shanghai 201804, China \\ ${ }^{2}$ Institute of Industrial Science, The University of Tokyo, Tokyo 153-8505, Japan \\ Correspondence should be addressed to Huwei Wu; 1133054@tongji.edu.cn
}

Received 6 July 2015; Accepted 27 October 2015

Academic Editor: Miguel Neves

Copyright (c) $2016 \mathrm{H}$. Wu and G. Wu. This is an open access article distributed under the Creative Commons Attribution License, which permits unrestricted use, distribution, and reproduction in any medium, provided the original work is properly cited.

\begin{abstract}
This paper describes a research work on driveline modeling, torsional vibration analysis, and clutch damper parameters optimization for reducing transmission gear rattle on the vehicle creeping condition. Firstly, major driveline components, including quasi-transient engine, multistage stiffness clutch damper, detailed manual transmission and differential mechanism, and LuGre tire, are modeled, respectively. Secondly, powertrain system modeling adopting a two-stage stiffness clutch damper is constructed and analyzed. Transient responses predicted by the model show that the driveline undergoes severe torsional vibration and transmission gear rattle phenomenon. By analysis, it is concluded that the clutch damper works jumping between the first- and second-stage stiffness, which results in this problem for the creeping condition. Then, a three-stage stiffness clutch damper is proposed innovatively to solve this problem. It is shown that severe driveline vibration and gear rattle phenomenon are inhibited effectively. Finally, it draws a conclusion that clutch damper parameters could have a great effect on driveline vibration and gear rattle phenomenon and a three-stage stiffness clutch damper could be utilized to solve gear rattle phenomenon efficiently on the vehicle creeping condition.
\end{abstract}

\section{Introduction}

Vibroimpacts in manual transmission (MT) are of critical concern to vehicle manufacturers based on noise, vibration, and reliability consideration. Gear rattle is a typical gear noise that is generated under the existence of torsional fluctuations, which, in turn, leads to gear teeth impact of unloaded gears fluctuating within tooth lash. The impact collision is transmitted to the transmission housing via shafts and bearings and then converted into an audible rattle noise, which is broadband in the frequency spectrum. Rattle noise has a distinct sound quality that differentiates it from other noises produced by other sources in the vehicle, which makes passengers usually annoyed by this noise and attribute it to some vehicle companies. So a better understanding of the dynamic behavior of drivelines and transmission gear rattle mechanism is in urgent need and has drawn many scholars' attention.

Gear rattle phenomenon is a comprehensive problem of the driveline that includes many nonlinearities of multistage clutch damper, gear meshing stiffness, gear backlash, drag torque, and so on. These nonlinearities make it difficult to analyze the mechanism for this phenomenon. Some attempts on numerical simulation and experiment studies are conducted in some literature.

In terms of numerical simulation, initial research on gear rattle focused on one gear pair. Nakamura firstly modeled one straight spur gear pair in which the time-varying meshing stiffness was equivalent to square wave function and static transmission error was the sum of harmonic Fourier series. It gave the moment of gear rattling clearly through the numerical simulation method [1]. Since then, many research scholars paid more attention to solving algorithms of mathematical models. Comparin and Singh utilized harmonic balance method to solve one gear pair rattling model, which arrived at the fact that there was two-side impact, one-side impact, or no impact with some parameters changing [2]. Kahraman and Singh found that one gear pair nonlinear property involved subharmonic response and chaos response by the numerical simulation method and harmonic balance 
method [3]. As the study continued, research object was transferred from one simple gear pair to complicated gear transmission system. Based on the four-degree-of-freedom model of one gear pair, Bozca et al. proposed empirical model and torsional vibration model based optimization of a 5speed gearbox design parameters to reduce rattle noise in an automotive transmission. Despite the geometric parameters optimization, overall rattle noise level was reduced and all optimized geometric design parameters also satisfied all constraints $[4,5]$. Besides, gear rattle problem is regarded as a comprehensive problem of the driveline system. Most of the driveline models used for the driveline torsional vibration analysis are lumped discrete models with a few degrees of freedom. Wang et al. described a model most early for torsional vibration of automotive manual transmission (MT) to analyze and predict gear rattle of all speeds. Accordingly, a rattle index was used to compare the rattle levels produced by different gear pairs. But in that model gear meshing stiffness was constant and self-excited vibration of timevarying stiffness was ignored [6]. Wu and Luan paid attention to the impact of gear meshing stiffness on the vehicle driveline torsional vibration and gave a comparison of simulation between variable meshing stiffness and averaged stiffness of loaded gear pairs based on overall powertrain system [7]. Robinette et al. developed a representative model for a front wheel drive (FWD) vehicle with MT by lumped parameter analysis and presented functional relations for torque losses associated with shafts, gears, seals, lubricating oil flow, and bearing clearance as a function of basic design parameters [8]. Drag torque including bearing friction torque, oil shearing torque, or oil churning torque was then validated by experimental results [9]. De La Cruz et al. considered different lubrication states influence of gear pairs on the rattle phenomenon and proposed a rattle index in consideration of lubrication state [10]. Fietkau and Bertsche proposed a simulation approach for loaded and unloaded gear contacts, which include oil films and elastic deformations. This approach is validated with experiment measurement and it is concluded that lubricant condition could not be ignored [11]. Theodossiades et al. took into consideration the effect of lubrication during engine idle conditions and examined the influence of lubrication in torsional vibration. It is shown that the lubricant film behaved as a time-varying nonlinear spring-damper element and could have a great influence on the gear rattle problem [12, 13]. Crowther et al. put forward 6-degree-of-freedom (DOF) model using a frequency sweep with engine excitation derived from measured data with two-stage gear meshing and an unloaded gear pair. It is found that the gear rattling is more severe when the engine speed passes the resonation frequency region of the system natural model. It concluded that an effective dynamic engine model is needed in order to get transient driveline component motion and then rattle phenomenon actually [14]. Bhagate et al. put forward a 6-DOF mathematical model for the torsional vibrations of front wheel drive automotive drivetrain and developed the optimization of sensitive system parameters for reducing the driveline rattle [15]. So as for transmission modeling, various factors such as gear pair time-varying stiffness, gear friction, bearing friction, and gear oil churning loss are in urgent need in the future modeling work.

In terms of rattle experiments, Couderc et al. designed and built early an experimental setup of a vehicle driveline for the prediction of the dynamic behavior of vehicle drivelines. It is concluded that the simulation model validated by the experimental setup could provide transient response truly [16]. Bellomo et al. analyzed the contribution of individual sound source to the overall rattle noise by means of noisesource analysis and proposed a pareto-optimal solution to reduce the rattle noise emission, utilizing a rattle test bench [17]. This improved test bench reproduced the branched driveline system, rather than the one-string driveline system in [16]. Forcelli et al. set up a virtual engine simulator for automotive transmission and conducted a parametric sensitivity study for amplitude of the torsional vibration. Moreover, a relationship between the vibroacoustics measurements and the human perception was found [18]. Barthod et al. analyzed the rattle threshold and the rattle noise evolution for different multiharmonic excitation parameters and mechanical gearbox parameters through a bench test [19]. Crowther and Rozyn introduced a gear rattle test rig, in which the electric motor drives the transmission at a steady mean speed via a double telescoping Hooke's joint. By changing the angle of the joints, the amplitude of the vibration could be adjusted [20]. Baumann and Bertsche built one gear pair test rig for rattle research and compared the rattle intensity under different lubricant oil condition. It is found that adopting high viscosity oil could inhibit rattle phenomenon when angular acceleration of the input shaft is larger [21]. Brancati et al. set up a specific test rig for one lightly loaded gear pair, which is able to acquire the relative rotation motion of gears by two high resolution incremental encoders. Based on measurement data from this test rig, a gear rattle metric based on the wavelet multiresolution analysis was proposed [22].

The clutch damper is a component of drivelines that could have significant influence on the torsional dynamic behavior of drivelines. Gear rattle phenomenon can be greatly reduced by opportunely setting some clutch parameters such as the multistage torsional springs. Steinel examined the influence of the twin-mass flywheel on the driveline natural characteristics and transient responses. It was shown that the twin-mass flywheel was the ideal solution for drivetrains of which the vibrations could not be reduced sufficiently if there was no need for the consideration of costs [23]. Prasad et al. found that elimination of gear rattle could be achieved by maximizing the hysteresis of clutch thereby absorbing the energy being transferred through the subjective and objective evaluation in the passenger bus experiment [24]. But it is obvious that maximizing the hysteresis of the clutch damper would reduce the transmission efficiency of the powertrain system. Xu et al. introduced a novel clutch damper with threestage stiffness and solved the rattle phenomenon effectively in low torque condition compared with the damper with twostage stiffness by vehicle experiments [25]. Similarly, many research scholars found that the clutch damper property plays an important role in reducing driveline vibration and rattle phenomenon $[26,27]$. 


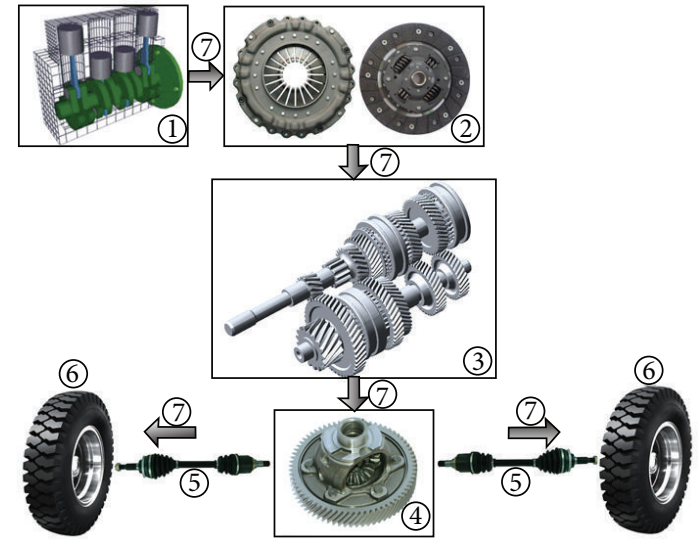

FIGURE 1: RWD vehicle powertrain system: (1) four-cylinder and four-stroke engine, (2) clutch damper, (3) manual transmission, (4) differential mechanism, (5) half axle, (6) wheel, and (7) power flow.

This paper presents a lumped parameters model capable of predicting the driveline vibration, the onset of loose gear rattle, and the clutch damper optimization for reducing loose gear rattle. Firstly, a description of the driveline and modeling of major components are presented. Then, the driveline model is used to perform transient analysis of current systems and provide a comprehensive understanding of a four-cylinder and four-stroke engine excitation, the strong nonlinearities of the driveline elements (including multistage clutch stiffness and frictional hysteresis), and parameter excitations of loaded gear pair meshing stiffness. The driveline model is divided into the baseline vibration and the rattling vibration. The baseline vibration is taken as the excitation to the rattling vibration and it is neglected that the rattling vibration has an effect on the baseline vibration. A detailed manual transmission modeling could reproduce the onset of rattle phenomenon of unloaded gear pairs. Finally, a comparison of the baseline vibration and the rattling vibration between using a two-stage stiffness clutch damper and using an improved three-stage stiffness clutch damper is studied on the vehicle creeping condition, which shows that it is achievable to optimize clutch damper parameters for reducing driveline vibration and gear rattle.

\section{Description and Modeling of Powertrain System}

A classical front wheel drive (FWD) vehicle is a research object. Major components of powertrain system, composed of an inline four-cylinder and four-stroke engine, the clutch damper, a 5-speed MT, the differential mechanism, half axles, and wheels, are as shown in Figure 1.

Effective modeling of powertrain components, which is discussed in this section, is vital to driveline vibration and manual transmission rattle phenomenon analysis. Quasitransient engine torque is as a power source to the driveline and applicable engine model should consider dynamic output torque rather than steady output torque in order to study

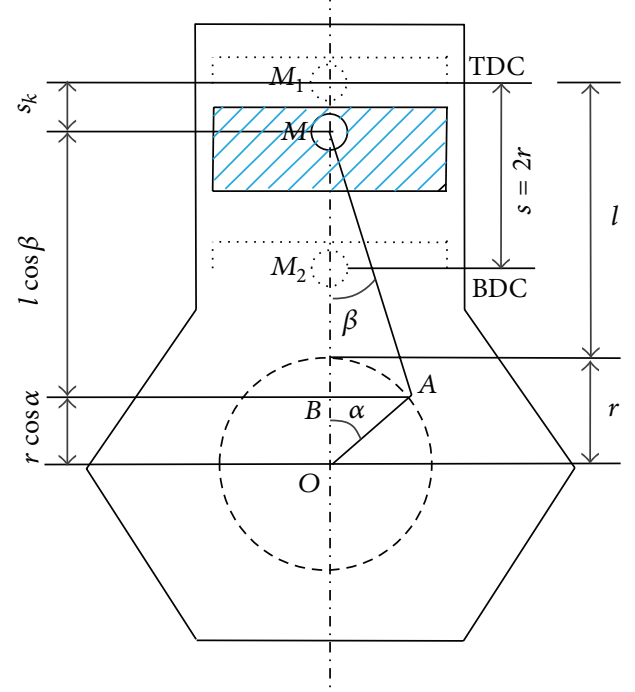

FIGURE 2: Kinematic relation of the crank and connecting rod mechanism.

transient response. The clutch damper in consideration of elastic torque and hysteresis torque is modeled so that clutch damper parameters affecting the driveline vibration and gear rattle could be analyzed. A detailed 5-speed manual transmission model based on lumped parameters method will also be explained. Simultaneously, the differential mechanism and the tire property are taken into consideration. Furthermore, time-varying meshing stiffness of loaded gear pairs is as an inner excitation in the driveline and accurate and effective calculation method of it could enhance simulation efficiency.

\subsection{Quasi-Transient Engine Model}

2.1.1. Kinematic Relations of a Single Cylinder. Kinematic diagram of the crank and connecting rod mechanism, which is shown in Figure 2, is calculated by

$$
\begin{aligned}
\alpha & =\omega \cdot t, \\
\lambda_{p} & =\frac{r}{l}, \\
s_{k} & =r\left(1+\frac{\lambda_{p}}{4}-\cos \alpha-\frac{\lambda_{p}}{4} \cos 2 \alpha\right), \\
\dot{s}_{k} & =\omega r\left(\sin \omega t+\frac{\lambda_{p}}{2} \sin 2 \omega t\right), \\
\ddot{s}_{k} & =\omega^{2} r\left(\cos \omega t+\lambda_{p} \cos 2 \omega t\right),
\end{aligned}
$$

where $\alpha$ is the crankshaft angle, $\omega$ is the crankshaft rotation angle speed, $t$ is the time, $r$ is the crank radius, $l$ is the connecting rod length, $s_{k}$ is the length between the top dead center and the piston center, and $\dot{s}_{k}, \ddot{s}_{k}$ are the translational velocity and acceleration of the piston, respectively. 


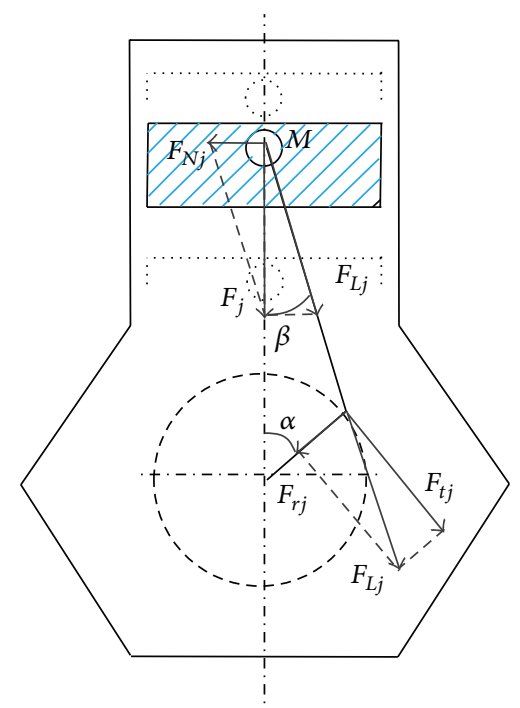

FIGURE 3: Force analysis of the crank and connecting rod mechanism.

2.1.2. Force Analysis of a Single Cylinder. Force analysis of the crank and connecting rod mechanism in Figure 3 is derived in

$$
\begin{aligned}
& F_{j}= \begin{cases}P_{g}(\alpha) \cdot \frac{\pi d_{p}^{2}}{4} & j=g \\
-m_{p} \cdot \ddot{s}_{k} & j=I,\end{cases} \\
& T_{g}=F_{g} r\left(\sin \alpha+\frac{\lambda_{p}}{2} \sin 2 \alpha\right), \\
& T_{I}=F_{I} r\left(\sin \alpha+\frac{\lambda_{p}}{2} \sin 2 \alpha\right),
\end{aligned}
$$

where $P_{g}(\alpha)$ is the cylinder pressure with the change of crank angle, $d_{p}$ is the piston diameter, $m_{p}$ is the reciprocating mass including piston, piston ring, piston pin, and connecting rod mass, $F_{g}$ is the gas pressure force on the piston, $T_{g}$ is the gas pressure torque, $F_{I}$ is the reciprocating mass force, and $T_{I}$ is the reciprocating mass torque.

2.1.3. Transient Engine Friction Model of a Single Cylinder. Engine friction modeling is a key step in the quasi-transient engine model. Transient engine friction model of RezekaHenein model is adopted here and engine friction torque $T_{f}$ is yielded by the following equation [28]:

$$
T_{f}=T_{f 1}+T_{f 2}+T_{f 3}+T_{f 4}+T_{f 5}+T_{f 6},
$$

where

$$
\begin{aligned}
& T_{f 1} \\
& \quad=c_{1}\left[\mu(r \omega|Z|)\left(P_{r}+P_{g}\right) w_{o}\right]^{0.5} d\left(n_{o}+0.4 n_{c}\right) r|Z|, \\
& T_{f 2}=c_{2} \pi d n_{c} w_{c}\left(P_{r}+P_{g}\right)(1-|\sin \alpha|) r|Z|, \\
& T_{f 3}=c_{3}\left(\mu \frac{\omega r Z}{h_{o}}\right) d L_{s} r Z,
\end{aligned}
$$

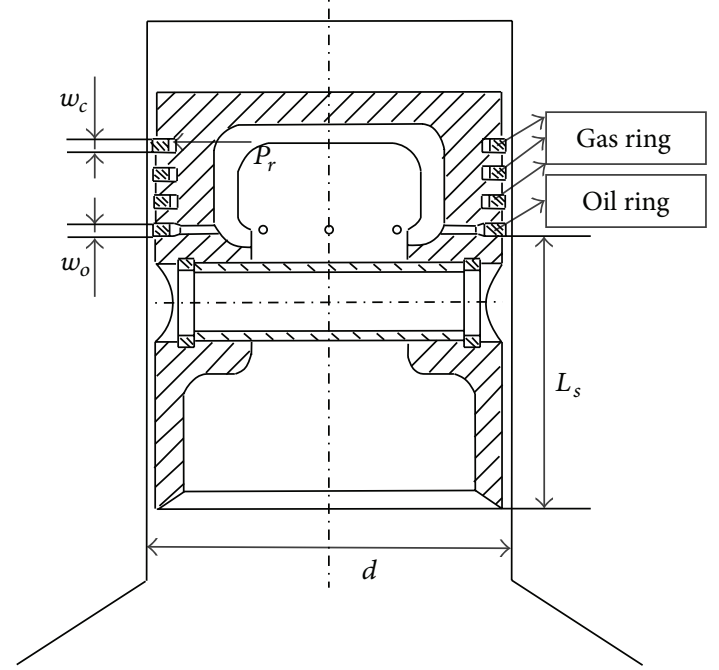

FIGURE 4: Some parameters for transient engine friction model.

$$
\begin{aligned}
& T_{f 4}=c_{4} n_{v} F_{s} r|Z| \omega^{-0.5}, \\
& T_{f 5}=c_{5} \mu \omega, \\
& T_{f 6}=c_{6} \frac{\pi d^{2}}{4} r_{j b} P_{g}|\cos \alpha| \omega^{-0.5}, \\
& Z=\sin \alpha+\frac{\lambda_{p} \sin \alpha \cos \alpha}{\sqrt{1-\lambda_{p}^{2} \sin ^{2} \alpha}},
\end{aligned}
$$

where $c_{i}(i=1,2, \ldots, 6)$ are fitting coefficients, $\mu$ is the kinematic viscosity of lubricant oil, $P_{r}$ is the contact pressure between piston ring and cylinder wall, $w_{o}$ is the thickness of oil ring, $d$ is the inner diameter of cylinder wall, $n_{o}$ is the number of oil rings, $n_{c}$ is the number of gas rings, $w_{c}$ is the thickness of gas ring, $h_{o}$ is the thickness of lubricating oil film, $L_{s}$ is the length of piston skirt, $n_{v}$ is the number of valves, $F_{s}$ is the force of valve spring, and $r_{j b}$ is the average radius of journal bearing. Some parameters are as shown in Figure 4.

\subsubsection{Effective Output Torque of an Inline Four-Cylinder and} Four-Stroke Engine. For an inline four-cylinder and fourstroke engine, effective output torque $T_{e}$ results from the gas torque, reciprocating inertia torque, and friction torque comprehensive in

$$
T_{e}=\sum_{j=1}^{4}\left(T_{g j}+T_{I j}-T_{f j}\right) .
$$

On the condition of vehicle creeping, engine speed is about $800 \mathrm{rpm}$ and each engine cylinder gas pressure is as seen in Figure 5. Accordingly, effective output torque of fourcylinder and four-stroke engine is as shown in Figure 6.

2.2. The Clutch Model. The clutch plays an important role in driveline vibration, especially in transmission rattle impact. 


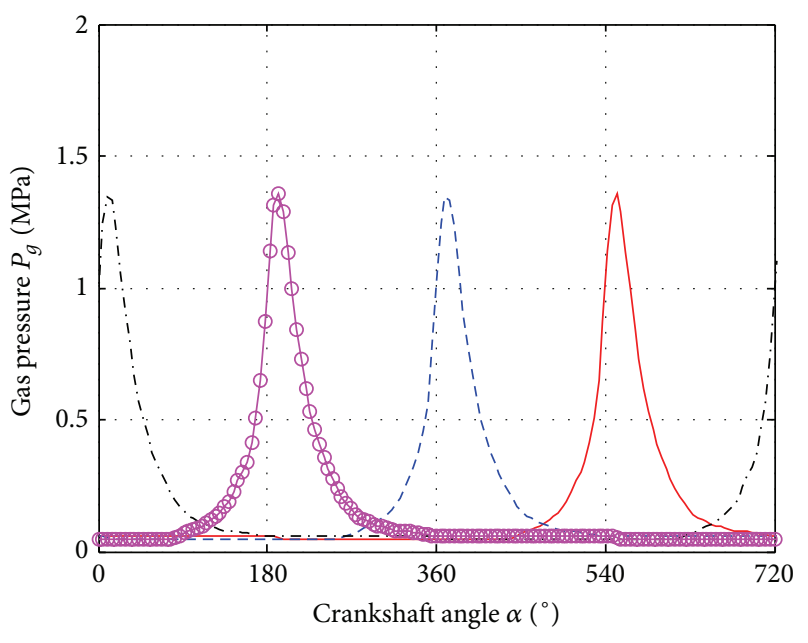

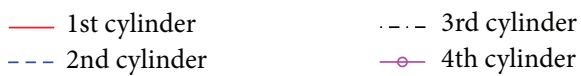

FIgURE 5: Each cylinder's gas pressures of the engine.

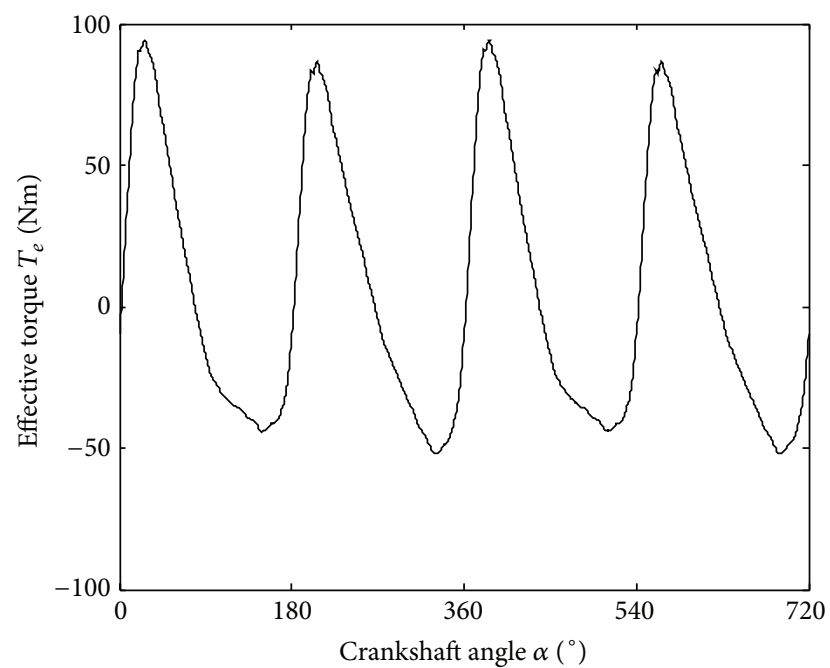

FIgURE 6: Effective output torque of the engine.

The clutch is composed of two parts or masses when it is engaged. The primary mass is attached to the flywheel rigidly (called the first mass together) and the secondary mass is connected to the input shaft of MT through spline teeth. Multistage springs are placed between the primary mass and the secondary mass.

For an asymmetric two-staged clutch damper in Figure $7(\mathrm{a})$, the clutch torque $T_{C}$ is expressed as a function of the relative displacement $\theta_{r}=\theta_{f}-\theta_{C}$ and the relative velocity $\dot{\theta}_{r}=\dot{\theta}_{f}-\dot{\theta}_{C}$ and is defined by the sum of elastic torque $T_{S}$ in Figure 7(b) and hysteresis torque $T_{H}$ in Figure 7(c) [26]:

$$
T_{C}\left(\theta_{r}, \dot{\theta}_{r}\right)=T_{S}\left(\theta_{r}\right)+T_{H}\left(\theta_{r}, \dot{\theta}_{r}\right) .
$$

The elastic torque $T_{S}$ is calculated in

$$
\begin{aligned}
& T_{S} \\
& = \begin{cases}k_{11}\left(\theta_{r}-\phi_{p 1}\right)+k_{12} \phi_{p 1} & \theta_{r}>\phi_{p 1} \\
k_{12} \theta_{r} & \phi_{p 2} \leq \theta_{r} \leq \phi_{p 1} \\
k_{21}\left(\theta_{r}-\phi_{p 2}\right)+k_{12} \phi_{p 2} & \phi_{p 3} \leq \theta_{r}<\phi_{p 2} \\
k_{22}\left(\theta_{r}-\phi_{p 3}\right)+k_{21}\left(\phi_{p 3}-\phi_{p 2}\right)+k_{12} \phi_{p 2} & \theta_{r}<\phi_{p 3},\end{cases}
\end{aligned}
$$

where $k_{12}$ is the first-stage stiffness, $k_{11}$ is the second-stage stiffness of the drive side, $k_{21}$ is the second-stage stiffness of the coast side, $k_{22}$ is the third-stage stiffness of the coast side, and $\phi_{p 1}, \phi_{p 2}$, and $\phi_{p 3}$ are the corresponding transition angles.

The hysteresis torque $T_{H}$ is defined in

$$
\begin{aligned}
& T_{H} \\
& = \begin{cases}\frac{H_{1}}{2}+\frac{H_{1}-H_{2}}{2} \operatorname{sgn}\left(\theta_{r}-\phi_{p 1}\right) & \dot{\theta}_{r}>0 \\
-\frac{H_{3}}{2}+\frac{H_{3}-H_{2}}{2} \operatorname{sgn}\left(\theta_{r}-\phi_{p 2}\right) & \dot{\theta}_{r}<0, \theta_{r}>\phi_{p 3} \\
-\frac{H_{4}}{2}+\frac{H_{4}-H_{2}}{2} \operatorname{sgn}\left(\theta_{r}-\phi_{p 3}\right) & \dot{\theta}_{r}<0, \theta_{r}<\phi_{p 3},\end{cases}
\end{aligned}
$$

where $H_{2}$ is the first-stage hysteresis torque, $H_{1}$ is the secondstage hysteresis torque of the drive side, $\mathrm{H}_{3}$ is the second-stage hysteresis torque of the coast side, and $\mathrm{H}_{4}$ is the third-stage hysteresis torque of the coast side.

For a three-staged clutch damper in Figure 7(d), the elastic torque $T_{S}^{\prime}$ and the hysteresis torque $T_{H}^{\prime}$ are defined in (9) and in (10), respectively. Consider

$$
\begin{aligned}
& T_{S}^{\prime} \\
& = \begin{cases}k_{11}\left(\theta_{r}-\phi_{p 1}\right)+k_{10}\left(\phi_{p 1}-\phi_{p 0}\right)+k_{12} \phi_{p 0} & \theta_{r}>\phi_{p 1} \\
k_{10}\left(\theta_{r}-\phi_{p 0}\right)+k_{12} \phi_{p 0} & \phi_{p 0}<\theta_{r} \leq \phi_{p 1} \\
k_{12} \theta_{r} & \phi_{p 2} \leq \theta_{r} \leq \phi_{p 0} \\
k_{21}\left(\theta_{r}-\phi_{p 2}\right)+k_{12} \phi_{p 2} & \phi_{p 3} \leq \theta_{r}<\phi_{p 2} \\
k_{22}\left(\theta_{r}-\phi_{p 3}\right)+k_{21}\left(\phi_{p 3}-\phi_{p 2}\right)+k_{12} \phi_{p 2} & \theta_{r}<\phi_{p 3},\end{cases} \\
& T_{H}^{\prime}= \begin{cases}\frac{H_{1}}{2}+\frac{H_{1}-H_{2}}{2} \operatorname{sgn}\left(\theta_{r}-\phi_{p 1}\right) & \dot{\theta}_{r}>0, \theta_{r}>\phi_{p 1} \\
\frac{H_{0}}{2}+\frac{H_{0}-H_{2}}{2} \operatorname{sgn}\left(\theta_{r}-\phi_{p 0}\right) & \dot{\theta}_{r}>0, \theta_{r}<\phi_{p 1} \\
-\frac{H_{3}}{2}+\frac{H_{3}-H_{2}}{2} \operatorname{sgn}\left(\theta_{r}-\phi_{p 2}\right) & \dot{\theta}_{r}<0, \theta_{r}>\phi_{p 3} \\
-\frac{H_{4}}{2}+\frac{H_{4}-H_{2}}{2} \operatorname{sgn}\left(\theta_{r}-\phi_{p 3}\right) & \dot{\theta}_{r}<0, \theta_{r}<\phi_{p 3},\end{cases}
\end{aligned}
$$

where $k_{10}$ is the second-stage stiffness of the three-staged clutch damper, $H_{0}$ is the corresponding hysteresis torque, and $\phi_{p 0}$ is the corresponding transition angles. 


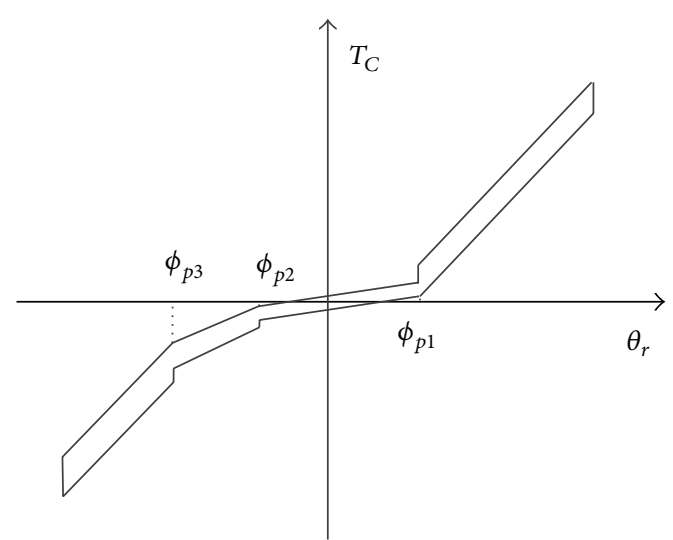

(a)

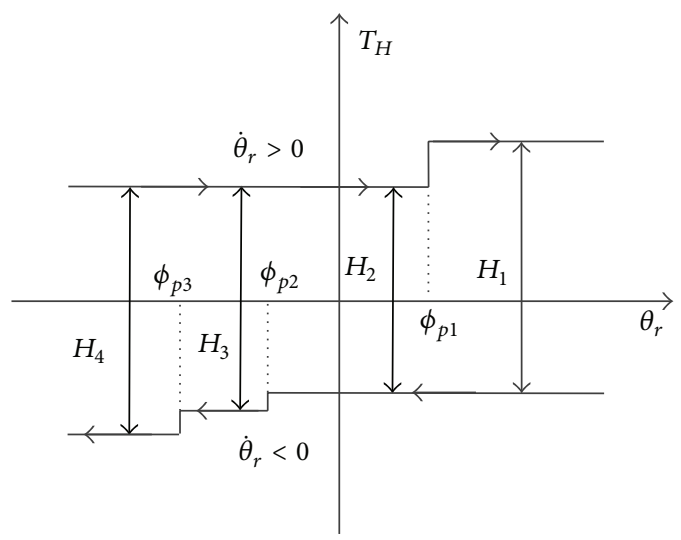

(c)

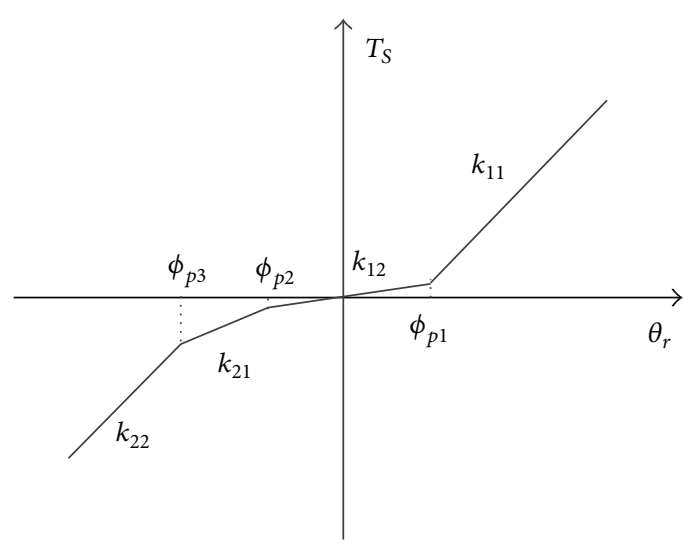

(b)

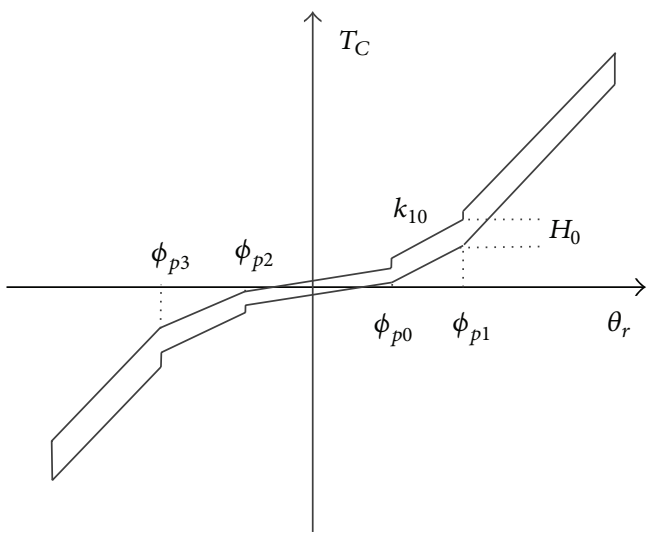

(d)

FIGURE 7: Nonlinear characteristics of a multistage clutch damper: (a) nonlinear characteristics of a two-stage clutch damper, (b) piecewise stiffness characteristics of the two-stage clutch damper, (c) piecewise hysteresis characteristics of the two-stage clutch damper, and (d) nonlinear characteristics of a three-stage clutch damper.

\subsection{Modeling of 5-Speed MT and Loose Gear Drag Torque}

2.3.1. MT Mechanism and Equivalent Physical Model. For the transverse 5-speed and two-axis design MT in Figure 8, which includes five forward gear ratios and one reverse gear ratio, input and output shafts are mounted on tapered roller element bearings. The 1st driven gear, 2 nd driven gear, $3 \mathrm{rd}$ driving gear, 4 th driving gear, and 5 th driving gear rotate on the input or output shaft through needle bearings. 1st driving and 2nd driving gear are integrated on the input shaft, while 3 rd driven, 4 th driven, and 5 th driven gear are splined on the output shaft. The 1st driven gear and 2 nd driven gear utilize the same triple cone synchronizer, which is supported by one hydrodynamic journal bearing, 3rd driving and 4th driving gears utilize one, and 5th driving gear utilizes another one.

Based on lumped parameter modeling method, every gear and synchronizer are equivalent to rotational inertias. The inertia of the segment shaft between two gears or between one gear and one synchronizer is divided into two parts averagely and they will be added on adjacent inertias, respectively. Simultaneously, the segment shaft is equivalent to one rotational stiffness and one rotational damping. Each inertia of one gear pair couples through meshing stiffness, meshing damping, and backlash and drag torques are applied on loose gears. The coupling between the input shaft and the output shaft is obtained by the power transmitting gear pair. The equivalent physical model of 5-speed MT consisting of an arrangement of discrete inertias and stiffness is as shown in Figure 9.

2.3.2. Calculation of Loose Gear Drag Torque. In Figure 9, drag torques $T_{D i}(i=1,2, \ldots, 5)$, acting on 1st driven gear, 2nd driven gear, 3rd driving gear, 4 th driving gear, and 5 th driving gear, are generated through bearing friction torque, oil shearing torque, or oil churning torque. Gear windage losses are ignored, since gear speeds are relatively low and loose gears on the input shaft are splash lubricated.

For the 1st speed driven and 2nd speed driven gear rotating on the output shaft, $T_{D 1}$ in (11) and $T_{D 2}$ in (12) are applied on the gears, respectively:

$$
\begin{aligned}
& T_{D 1}=T_{r b 1}+T_{\mathrm{sh} 1}+T_{\mathrm{ch} 1}, \\
& T_{D 2}=T_{r b 2}+T_{\mathrm{sh} 2}+T_{\mathrm{ch} 2} .
\end{aligned}
$$




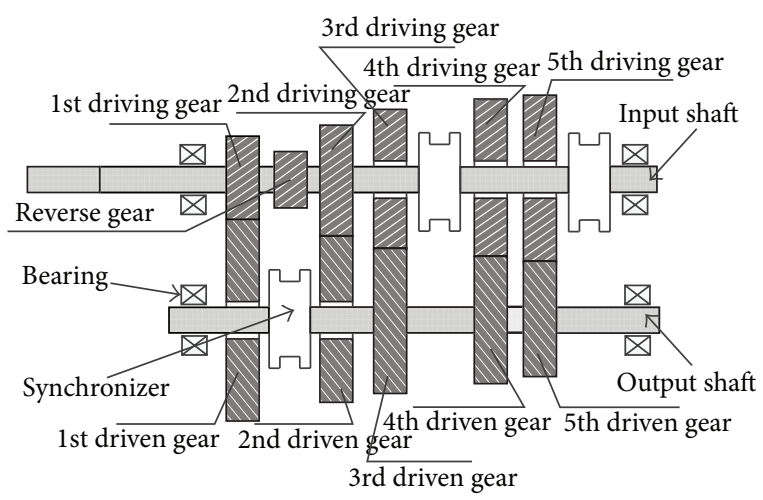

FIGURE 8: Mechanical structure of 5-speed MT.

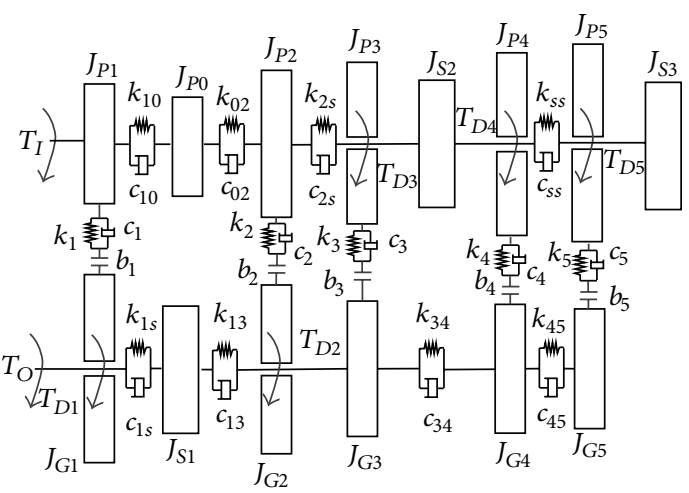

FIGURE 9: Equivalent physical model of 5-speed MT.

Bearing frictional torque $T_{r b i}$ is defined in the following equation [29]:

$$
\begin{aligned}
& T_{r b i}=10^{3} f_{0}(\nu N)^{2 / 3} d_{m}^{3} \quad v N \geq 2 \times 10^{-3}, \\
& T_{r b i}=16 f_{0} d_{m}^{3} \quad \nu N<2 \times 10^{-3},
\end{aligned}
$$

where $N$ is the bearing rotation speed, $d_{m}$ is the bearing average diameter, $f_{0}$ is a lubrication factor, and $\nu$ is lubrication oil kinematic viscosity.

Oil shearing torque $T_{\mathrm{sh} i}(i=1,2)$ is defined in the following equation [8]:

$$
T_{\mathrm{sh} i}=\frac{4 \pi^{2} \mu L R^{3} \Delta N}{30 j j},
$$

where $\mu$ is the lubrication oil absolute viscosity, $L$ is the gear length, $R$ is the pitch radius of the gear, $\Delta N$ is speed differential between the gear and synchronizer or its bounding shaft, and $j j$ is the radial clearance of the bearing.

Oil churning torque $T_{\mathrm{ch} i}(i=1,2)$ is defined in the following equation [30]:

$$
T_{\mathrm{ch} i}=\frac{1}{2} \rho \omega_{g}^{2} S_{m} R^{3} C_{m}
$$

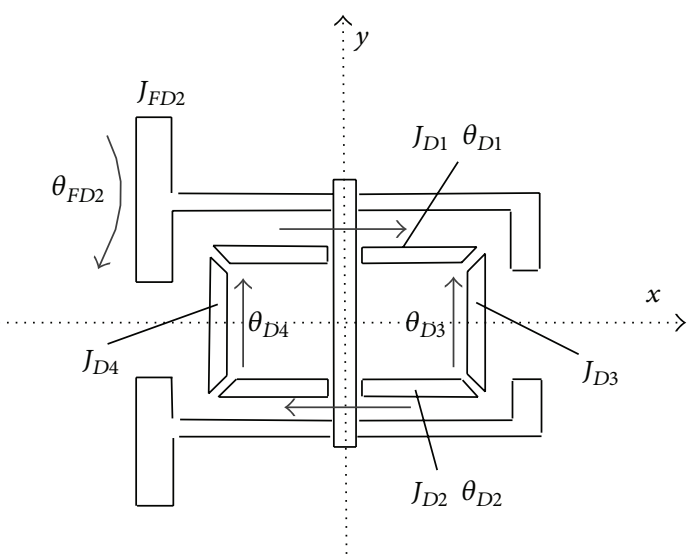

Figure 10: Structure diagram of the differential.

where $\rho$ is the lubrication oil density, $\omega_{g}$ is the gear oil churning angle velocity, $S_{m}$ is the oil-submerged surface area, and $C_{m}$ is the oil churning coefficient.

For the unloaded 3rd driving gear, 4th driving gear, and 5 th driving gear rotating on the output shaft affected by bearing friction, drag torque $T_{D 3}$ in (16), drag torque $T_{D 4}$ in (17), and drag torque $T_{D 5}$ in (18) are applied on the gears, respectively:

$$
\begin{aligned}
& T_{D 3}=T_{r b 3}, \\
& T_{D 4}=T_{r b 4}, \\
& T_{D 5}=T_{r b 5} .
\end{aligned}
$$

2.4. The Differential Model. The bevel gear differential mechanism assembly and kinetic relation of each part are as shown in Figure 10. Rotational angle relation is defined in

$$
\begin{aligned}
2 \theta_{F D 2} & =\theta_{D 3}+\theta_{D 4}, \\
\theta_{D 1} & =\frac{i_{d}}{2}\left(\theta_{D 4}-\theta_{D 3}\right), \\
\theta_{D 2} & =\frac{i_{d}}{2}\left(\theta_{D 3}-\theta_{D 4}\right),
\end{aligned}
$$

where $\theta_{F D 2}$ is the assembly rotational angle of the final gear, the differential housing, and the planetary-gear pin around the $x$-axis, $\theta_{D i}(i=3,4)$ is the rotational angle of the half axle gear around the $x$-axis, $\theta_{D i}(i=1,2)$ is the rotational angle of the planetary gear around the $y$-axis, and $i_{d}$ is the speed ratio of the planetary gear to the half axle gear.

Defining $\theta_{F D 2}$ and $\theta_{D 4}$ as generalized coordinates, other rotational angles could be presented by these two coordinates:

$$
\begin{aligned}
& {\left[\begin{array}{lllll}
\theta_{F D 2} & \theta_{D 4} & \theta_{D 3} & \theta_{D 1} & \theta_{D 2}
\end{array}\right]^{T}} \\
& =\left[\begin{array}{ccccc}
1 & 0 & 2 & -i_{d} & i_{d} \\
0 & 1 & -1 & i_{d} & -i_{d}
\end{array}\right]^{T}\left[\begin{array}{ll}
\theta_{F D 2} & \theta_{D 4}
\end{array}\right]^{T} .
\end{aligned}
$$




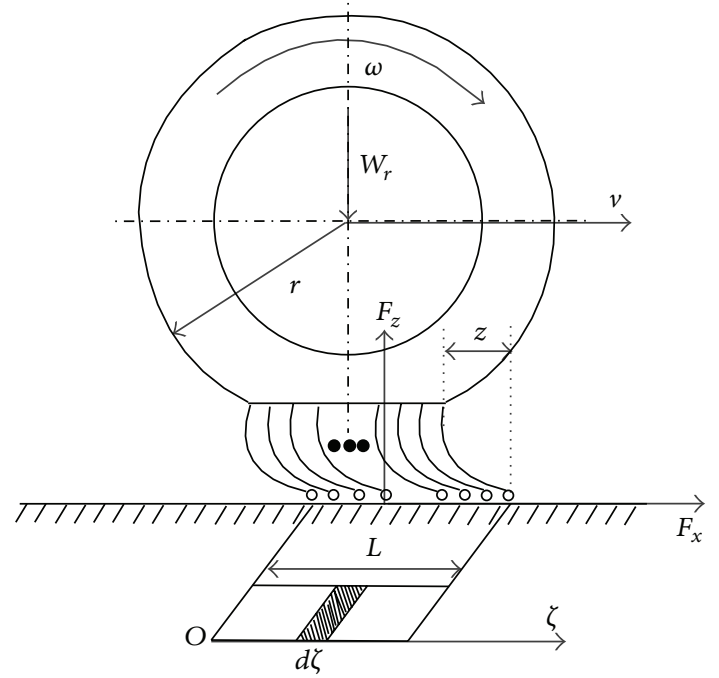

FIGURE 11: The LuGre tire model.

Now, the kinetic energy $\mathbf{T}_{d f}$ of the differential assembly is calculated by

$$
\begin{aligned}
& \mathbf{T}_{d f}=\frac{1}{2}\left[\begin{array}{c}
\dot{\theta}_{F D 2} \\
\dot{\theta}_{D 4} \\
\dot{\theta}_{D 3} \\
\dot{\theta}_{D 1} \\
\dot{\theta}_{D 2}
\end{array}\right]^{T}\left[\begin{array}{ccccc}
J_{F D 2} & & & & \\
& J_{D 4} & & \mathbf{0} & \\
& & J_{D 3} & & \\
& \mathbf{0} & & J_{D 1} & \\
& & & & J_{D 2}
\end{array}\right]\left[\begin{array}{c}
\dot{\theta}_{F D 2} \\
\dot{\theta}_{D 4} \\
\dot{\theta}_{D 3} \\
\dot{\theta}_{D 1} \\
\dot{\theta}_{D 2}
\end{array}\right] \\
& =\frac{1}{2}\left[\begin{array}{c}
\dot{\theta}_{F D 2} \\
\dot{\theta}_{D 4}
\end{array}\right]^{T} \mathbf{J}_{d f}\left[\begin{array}{c}
\dot{\theta}_{F D 2} \\
\dot{\theta}_{D 4}
\end{array}\right],
\end{aligned}
$$

$$
\begin{aligned}
& \mathbf{J}_{d f} \\
& =\left[\begin{array}{cc}
J_{F D 2}+4 J_{D 3}+i_{d}^{2} J_{D 1}+i_{d}^{2} J_{D 2} & -2 J_{D 3}-i_{d}^{2} J_{D 1}-i_{d}^{2} J_{D 2} \\
-2 J_{D 3}-i_{d}^{2} J_{D 1}-i_{d}^{2} J_{D 2} & J_{D 4}+J_{D 3}+i_{d}^{2} J_{D 1}+i_{d}^{2} J_{D 2}
\end{array}\right],
\end{aligned}
$$

where $J_{F D 2}$ is the rotational inertia of the assembly rotational angle of the final gear, the differential housing, and the planetary-gear pin around the $x$-axis, $J_{D i}(i=3,4)$ is the rotational inertia of the half axle gear around the $x$-axis, and $J_{D i}(i=1,2)$ is the rotational inertia of the planetary gear around the $y$-axis.

2.5. The LuGre Tire Model. For the LuGre tire model, the force analysis and the motion diagram are as shown in Figure 11.

The force analysis of the average lumped LuGre tire model is given by the following equation [31]:

$$
\begin{aligned}
\frac{d z}{d t} & =v_{r}-\frac{\sigma_{0}\left|v_{r}\right|}{g\left(v_{r}\right)} z, \\
g\left(v_{r}\right) & =\mu_{c}+\left(\mu_{s}-\mu_{c}\right) e^{-\left(v_{r} / v_{s}\right)^{\lambda}}, \\
F_{x} & =\int_{0}^{L}\left(\sigma_{0} z+\sigma_{1} \dot{z}+\sigma_{2} v_{r}\right) f_{n}(\zeta) d \zeta,
\end{aligned}
$$

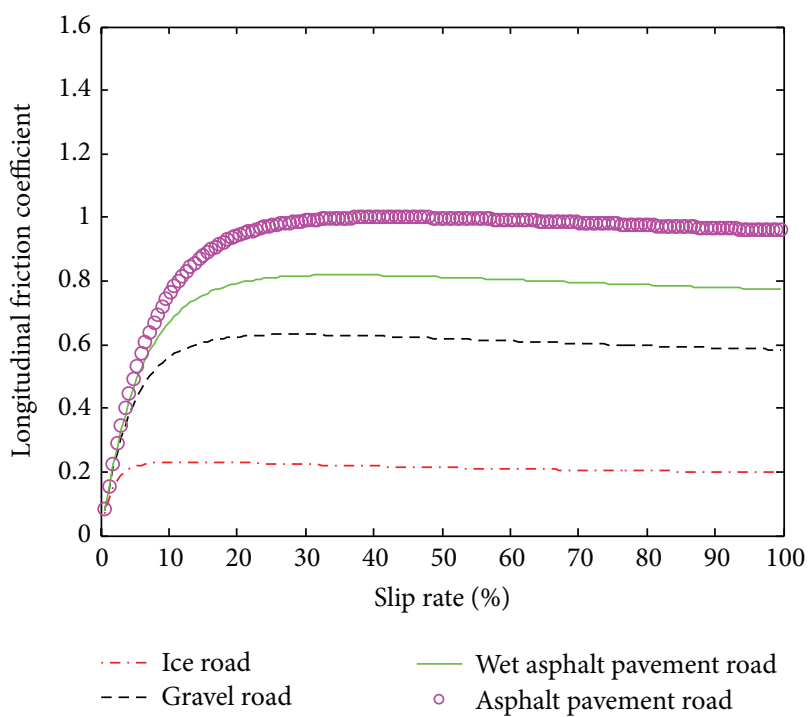

FIGURE 12: The LuGre tire property for different road.

$$
\begin{aligned}
F_{z} & =\int_{0}^{L} f_{n}(\zeta) d \zeta, \\
s & = \begin{cases}\frac{\omega r-v}{\omega r}=\frac{v_{r}}{\omega r} & \text { driving } \\
\frac{v-\omega r}{v}=\frac{v_{r}}{v} & \text { braking, }\end{cases} \\
\mu & =\frac{F_{x}}{F_{z}}
\end{aligned}
$$

where $z$ is the average deformation of brush, $v_{r}$ is the relative velocity between the tire and the ground, $\sigma_{0}$ is the normalized rubber longitudinal lumped stiffness, $\sigma_{1}$ is the normalized rubber longitudinal lumped damping, $\sigma_{2}$ is the normalized viscous relative damping, $\mu_{c}$ is the normalized coulomb friction, $\mu_{s}$ is the normalized static friction, $v_{s}$ is the Stribeck relative velocity, $\lambda$ is the Stribeck effect index, $L$ is the length of the contact patch, $f_{n}(\zeta)$ is the distribution density function of the longitudinal pressure, $F_{x}$ is the longitudinal force of the tire, $F_{z}$ is the vertical force of the tire, $s$ is the tire slip rate, $\omega$ is the rotational velocity of the tire, $r$ is the rolling radius of the tire, and $\mu$ is the longitudinal road friction coefficient.

By the LuGre model, the relation between the longitudinal road friction coefficient $\mu$ and the tire slip rate $s$ on different ground condition is obtained in Figure 12.

2.6. Calculation of Gear Pair Time-Varying Meshing Stiffness. Finite element analysis (FEA) is the most effective method for helical gear pair time-varying meshing stiffness. The helical gear meshing stiffness is defined as

$$
\begin{aligned}
& k=\frac{F_{n}}{\varepsilon}, \\
& \varepsilon=\varepsilon_{b s 1}+\varepsilon_{b s 2}+\varepsilon_{c},
\end{aligned}
$$


where $k$ is the gear pair meshing stiffness, $F_{n}$ is the normal force of the contact force, $\varepsilon$ is the comprehensive deformation of gear pair, $\varepsilon_{b s 1}$ is the bending and shear deformation of one gear on the contact point, $\varepsilon_{b s 2}$ is the bending and shear deformation of the other gear on the contact point, and $\varepsilon_{c}$ is the contact deformation of the gear pair on the contact point.

Simon got the bending and shear deformation $\varepsilon_{b s i}(i=$ $1,2)$, computational formula of (24), based on large amounts of FEA results through regression analysis [32]. Therefore,

$$
\begin{aligned}
\varepsilon_{b s i}= & \frac{1515.37 F_{n}}{E m_{n}} f_{1} f_{2} f_{3} z^{-1.0622}\left(\frac{\alpha_{n}}{20}\right)^{-0.3879} \\
& \cdot\left(1+\frac{\beta_{0}}{10}\right)^{0.08219}\left(1+\chi_{p}\right)^{-0.2165}\left(\frac{h_{f}}{m_{n}}\right)^{0.5563} \\
& \cdot\left(\frac{h_{k}}{m_{n}}\right)^{0.6971}\left(\frac{r_{\mathrm{fil}}}{m_{n}}\right)^{0.00043}\left(\frac{b}{m_{n}}\right)^{-0.6040},
\end{aligned}
$$

where $E$ is the elastic modulus, $m_{n}$ is the normal module, $f_{1}$ is the coefficient of normal force load point, $f_{2}$ is the coefficient of the relative radial position between load point and deformation point, $f_{3}$ is the coefficient of the relative axial position between load point and deformation point, $z$ is the teeth number, $\alpha_{n}$ is the normal pressure angle, $\beta_{0}$ is the spiral angle in base on base circle, $\chi_{p}$ is the gear modification coefficient, $h_{f}$ is the addendum, $h_{k}$ is the dedendum, $r_{\text {fil }}$ is the tooth root fillet radius, and $b$ is the tooth width.

As for the contact deformation $\varepsilon_{c}$, Cornell derived the following equation [33]:

$$
\begin{aligned}
\varepsilon_{c}= & \frac{2 \Delta F}{\pi \Delta z}\left\{k_{1}\left[\ln \left(\frac{s_{1}}{b_{e}}\right)-\frac{v_{1}}{2\left(1-v_{1}\right)}\right]\right. \\
& \left.+k_{2}\left[\ln \left(\frac{s_{2}}{b_{e}}\right)-\frac{v_{2}}{2\left(1-v_{2}\right)}\right]\right\}, \\
b_{e}= & \sqrt{\frac{4 \Delta F r_{1} r_{2}\left(k_{1}+k_{2}\right)}{\pi \Delta z\left(r_{1}+r_{2}\right)}}, \\
k_{1}= & \frac{1-v_{1}^{2}}{E_{1}} \\
k_{2}= & \frac{1-v_{2}^{2}}{E_{2}},
\end{aligned}
$$

where $\Delta z$ is the piece length along the tooth width, $\Delta F$ is the piece force applied on the piece length $\Delta z, s_{1}$ is the tooth thickness of one gear, $s_{2}$ is the tooth thickness of the other gear, $v_{1}$ is Poisson's ratio of one gear, $v_{2}$ is Poisson's ratio of the other gear, $E_{1}$ is the elastic modulus of one gear, and $E_{2}$ is the elastic modulus of the other gear.

Through (23) to (25), the time-varying meshing stiffness $k_{1}$ of the 1st gear pair (as shown in Figure 9) and the final drive gear pair $k_{f}$ (as shown in Figure 16) for a two-tooth cycle are shown in Figures 13 and 14.

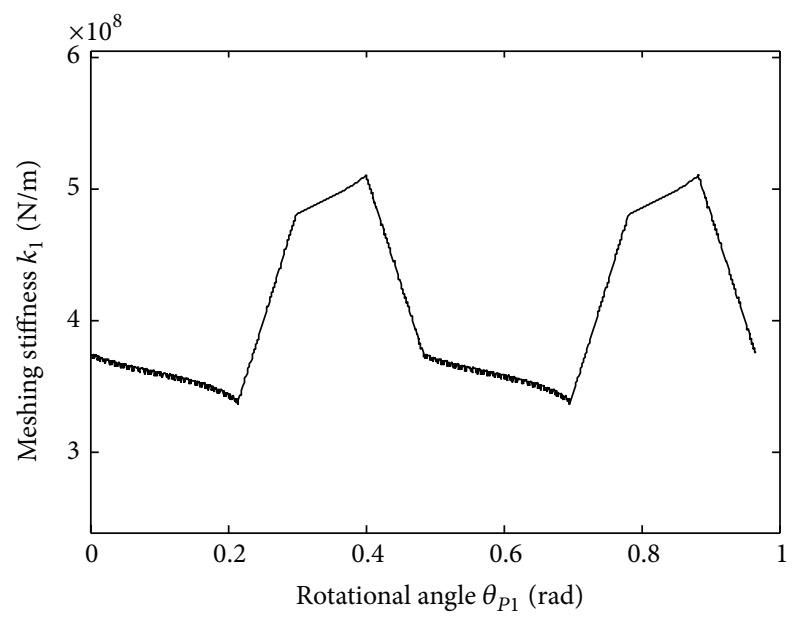

FIGURE 13: The meshing stiffness of 1st gear pair.

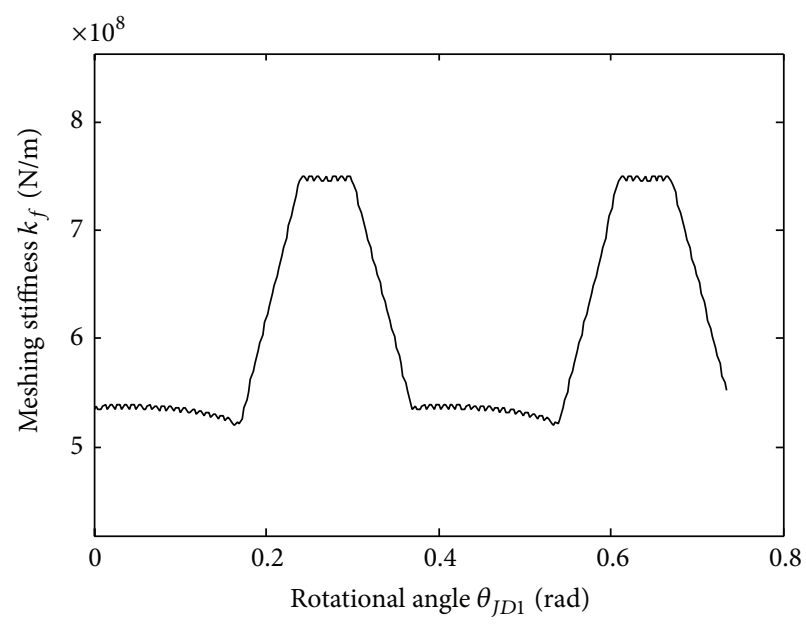

FIGURE 14: The meshing stiffness of final drive gear pair.

\section{Numerical Modeling and Simulation Algorithm}

3.1. Modeling Framework. The 1st shift of MT on the vehicle creeping condition, when gear rattle noise could be perceived clearly by passengers on the researched vehicle, is used as an example. Gear rattle phenomenon is comprehensive results of complex interactions between the baseline vibration for the loaded driveline system and the rattling vibration for unloaded gear pairs in Figure 15. The baseline vibration consists of the engine, the clutch, the 1st gear pair, gears integrated on the input shaft, gears splined on the output shaft, final drive gear pair, the differential, the haft shaft, and the tire, while the rattling vibration concludes lightly loaded gear pairs, namely, the 2 nd, the $3 \mathrm{rd}$, the 4 th, and the 5 th gear pair.

It has been widely recognized in literature that the rattling vibration has little effects on the motion of the baseline vibration $[6,14]$, which could be utilized to study the overall system behavior more efficiently. The pinion gear motions of lightly loaded gear pairs in the baseline vibration become 


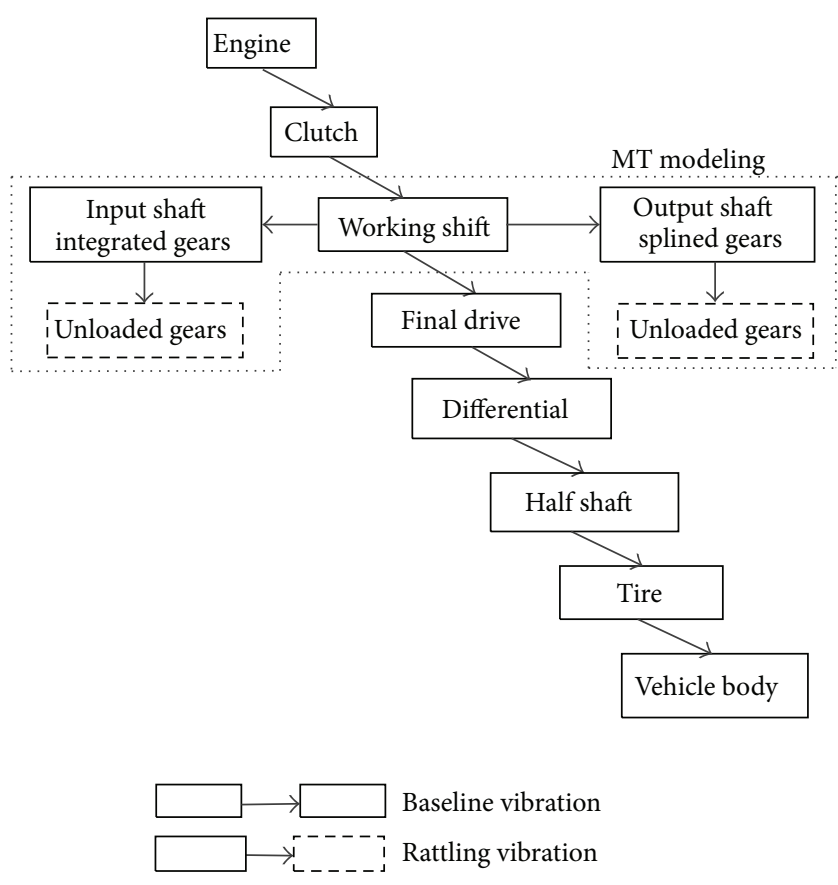

FIGURE 15: Modeling framework for driveline vibration and gear rattle phenomenon.

excitations to loose gear pairs in the rattling vibration. Then, the rattle force of loose gear pairs could be obtained.
3.2. The Baseline Model of Vehicle Driveline System. Dynamic FWD driveline model based on the branched model is described in Figure 16 when the 1st gear pair is engaged. These loaded gear pairs, namely, the 1st gear pair and the final drive gear pair, are considered to be always in contact with a timevarying meshing stiffness, respectively, which is calculated in Section 2.6. Those unloaded gear pairs with lighted load may be driven across the backlash, causing impacts and rattle noise. The driveline model consists of the two-stage stiffness clutch damper model and the detailed MT model, considers the differential property, and utilizes the average lumped parameters LuGre tire model. The input power of driveline system is the effective output torque of the four-cylinder and four-stroke engine. Accordingly, the longitudinal force analysis of the vehicle and the torsional force analysis of the tire are as shown in Figure 17, assuming that vertical left and right tires load of the front or rear axle are equivalent.

In the branched model, the simplified factors include (1) ignoring the oil shearing torque and the oil churning torque applied on the 1st gear pair in the power flow and (2) neglecting dynamic property influence of bearings on the input shaft and the output shaft in Figure 8 and final drive gear bearings.

By the Lagrange equation, the baseline system vibration dynamics is placed in the matrix form:

$$
\mathbf{J} \ddot{\boldsymbol{\theta}}(t)+\mathbf{K} \boldsymbol{\theta}(t)+\mathbf{C} \dot{\boldsymbol{\theta}}(t)=\mathbf{T}(t),
$$

where

$$
\begin{aligned}
& \boldsymbol{\theta}=\left[\begin{array}{llllllllllllllllllll}
\theta_{f} & \theta_{C} & \theta_{P 1} & \theta_{P 0} & \theta_{P 2} & \theta_{S 2} & \theta_{S 3} & \theta_{G 1 S 1} & \theta_{G 3} & \theta_{G 4} & \theta_{G 5} & \theta_{F D 1} & \theta_{F D 2} & \theta_{D 4} & \theta_{s l} & \theta_{s r} & \theta_{t l} & \theta_{t r} & x_{s}
\end{array}\right]^{T}, \\
& \mathbf{T}=\left[\begin{array}{llllllllllllllllllll}
T_{e}-T_{c} & T_{c} & 0 & 0 & 0 & 0 & 0 & 0 & 0 & 0 & 0 & 0 & 0 & 0 & 0 & 0 & -T_{g l} & -T_{g r} & F_{x f l}+F_{x f r}-F_{x r}-F_{w}
\end{array}\right]^{T},
\end{aligned}
$$

$$
\mathrm{J}=\left[\begin{array}{lll}
\mathrm{J}_{1} & \mathbf{0} & \mathbf{0} \\
\mathbf{0} & \mathrm{J}_{2} & \mathbf{0} \\
\mathbf{0} & \mathbf{0} & \mathrm{J}_{3}
\end{array}\right],
$$

$K=\left[\begin{array}{ccc}K_{11} & K_{12} & 0 \\ K_{21} & K_{22} & 0 \\ 0 & 0 & 0\end{array}\right]$,

$$
C=\left[\begin{array}{ccc}
C_{11} & C_{12} & 0 \\
C_{21} & C_{22} & 0 \\
0 & 0 & 0
\end{array}\right] \text {, }
$$

$\mathbf{J}_{\mathbf{1}}=\operatorname{diag}\left(\left[\begin{array}{llllllllllll}J_{f} & J_{C} & J_{P 1} & J_{P 0} & J_{P 2} & J_{S 2} & J_{S 3} & J_{G 1 S 1} & J_{G 3} & J_{G 4} & J_{G 5} & J_{F D 1}\end{array}\right]\right)$,

$\mathbf{J}_{2}=\left[\begin{array}{cc}J_{F D 2}+4 J_{D 3}+i_{d}^{2} J_{D 1}+i_{d}^{2} J_{D 2} & -2 J_{D 3}-i_{d}^{2} J_{D 1}-i_{d}^{2} J_{D 2} \\ -2 J_{D 3}-i_{d}^{2} J_{D 1}-i_{d}^{2} J_{D 2} & J_{D 4}+J_{D 3}+i_{d}^{2} J_{D 1}+i_{d}^{2} J_{D 2}\end{array}\right]$,

$\mathbf{J}_{\mathbf{3}}=\operatorname{diag}\left(\left[\begin{array}{lllll}J_{s l} & J_{s r} & J_{t l} & J_{t r} & m\end{array}\right]\right)$, 


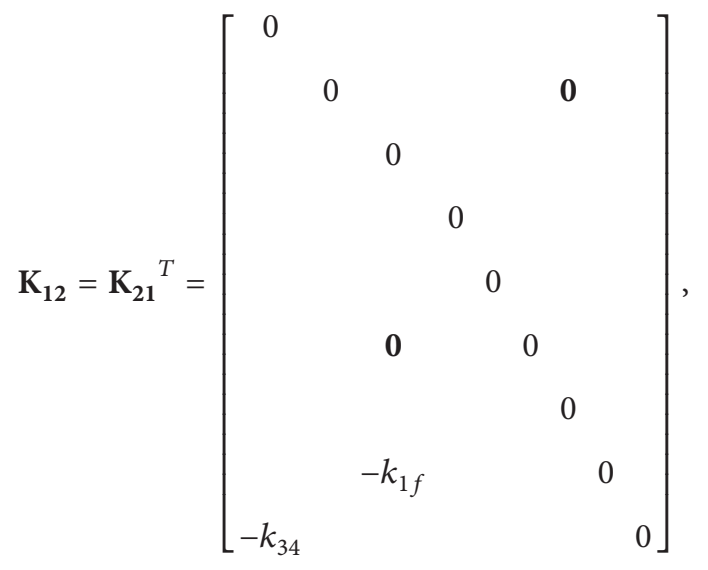

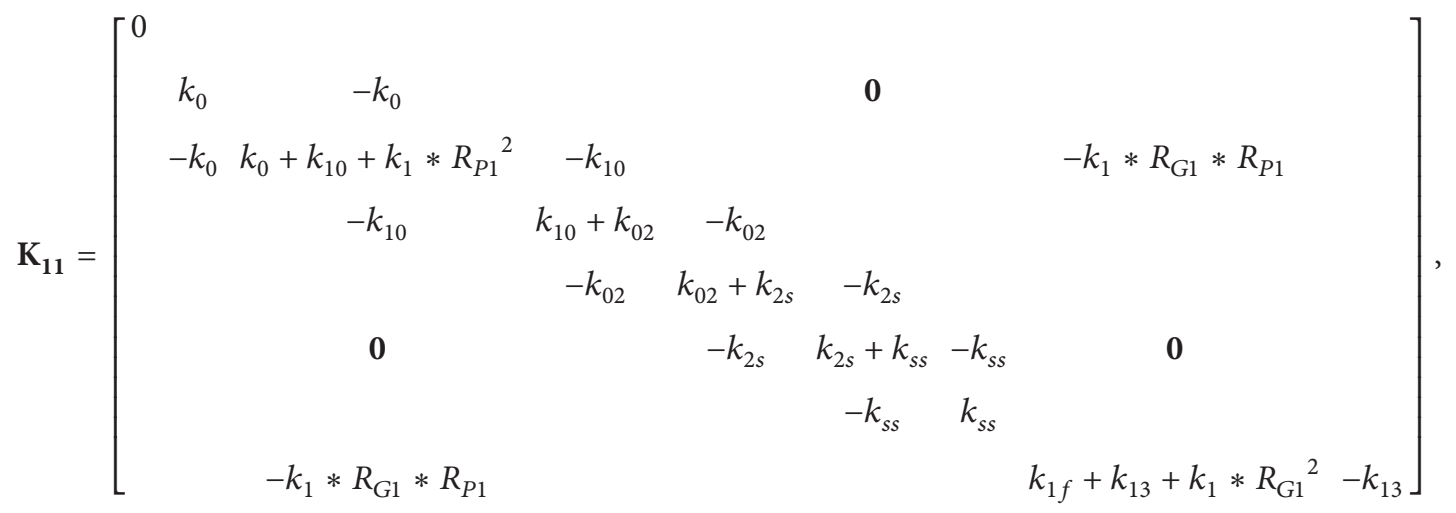

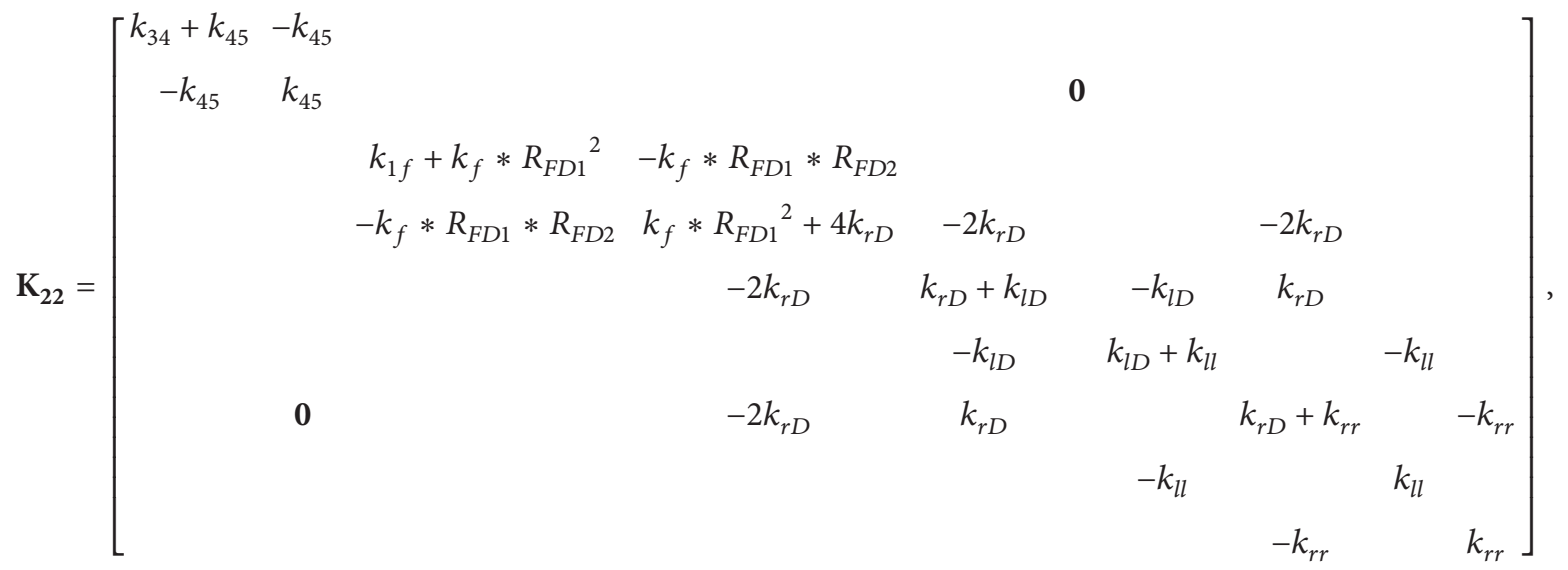

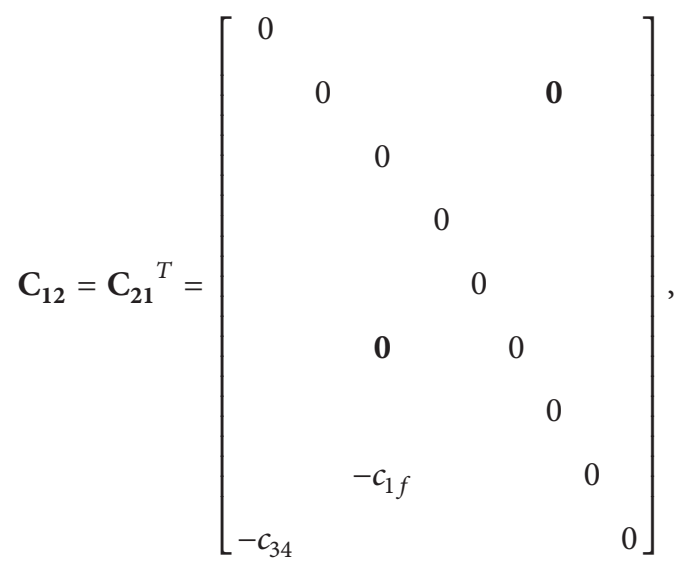




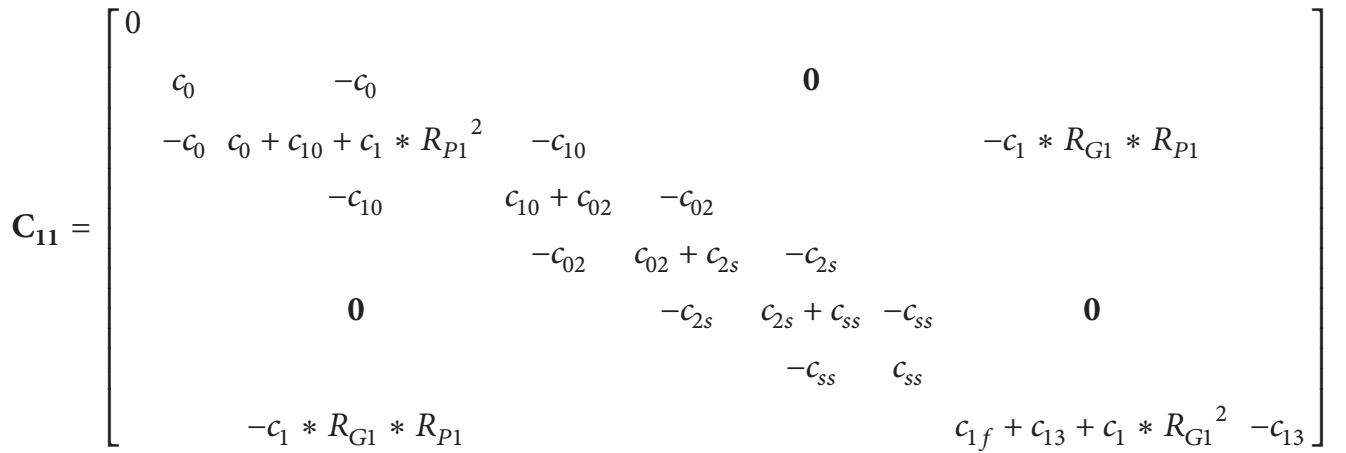

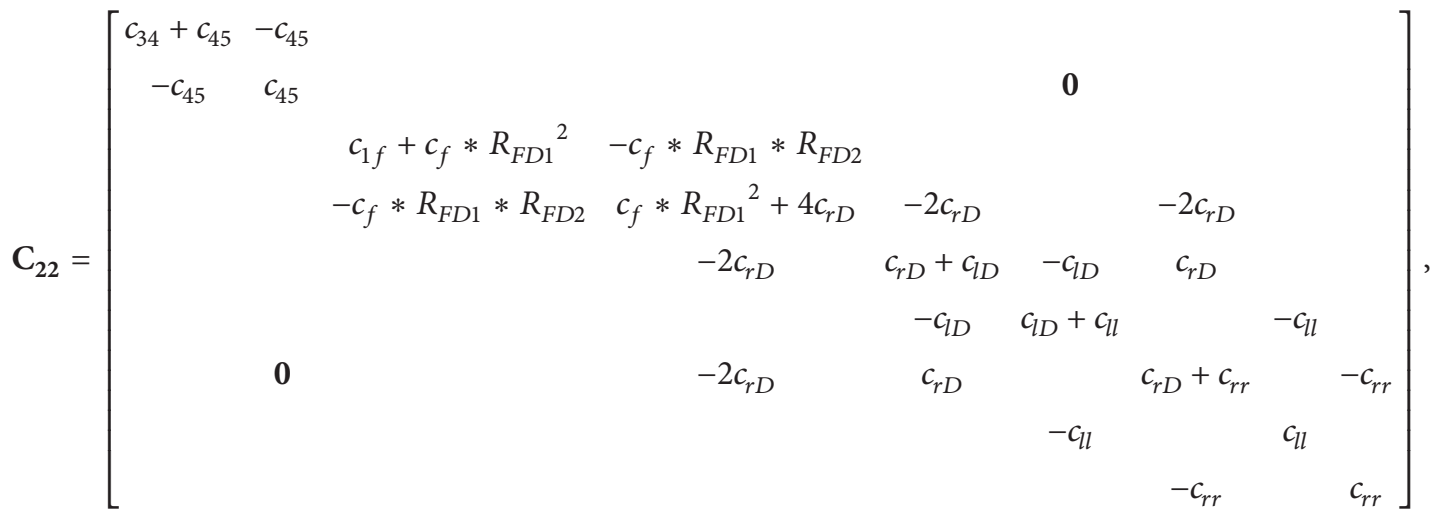

where diag expresses the diagonal matrix, $\theta_{f}$ is the angular displacement $(\mathrm{AD})$ of engine (namely, the flywheel and clutch), $\theta_{C}$ is the $\mathrm{AD}$ of clutch hub, $\theta_{P 1}$ is the pinion gear $\mathrm{AD}$ of the 1st gear pair, and $\theta_{G 1 S 1}$ is the wheel gear of the 1st gear pair and the corresponding synchronizer AD. $\theta_{P 2}$ and $\theta_{G 2}$ are the $\mathrm{AD}$ of the 2 nd gear pair, $\theta_{P 3}$ and $\theta_{G 3}$ are the $\mathrm{AD}$ of the $3 \mathrm{rd}$ gear pair, $\theta_{P 4}$ and $\theta_{G 4}$ are the AD of the 4 th gear pair, $\theta_{P 5}$ and $\theta_{G 5}$ are the $\mathrm{AD}$ of the 5 th gear pair, $\theta_{S 2}$ is the $\mathrm{AD}$ of the $3 \mathrm{rd}$ and 4 th gear pair synchronizer, $\theta_{S 3}$ is the AD of the 5 th gear pair synchronizer, $\theta_{F D 1}$ and $\theta_{F D 2}$ are the $\mathrm{AD}$ of the final drive gear pair, $\theta_{D 4}$ is the AD of a half axle gear about its own rotational axis, $\theta_{s l}$ and $\theta_{s r}$ are $\mathrm{AD}$ of left and right half axle, $\theta_{t l}$ and $\theta_{t r}$ are the $\mathrm{AD}$ of left and right tire, $x_{s}$ is the vehicle longitudinal displacement, $J_{f}$ is the inertia of flywheel and clutch, $J_{C}$ is the inertia of clutch hub, $J_{P 1}$ is the pinion gear inertia of the 1st gear pair, and $J_{G 1 S 1}$ is the sum of the wheel gear inertia of the 1st gear pair and the corresponding synchronizer. $J_{P 2}$ and $J_{G 2}$ are the inertia of the 2 nd gear pair, $J_{P 3}$ and $J_{G 3}$ are the inertia of the 3 rd gear pair, $J_{P 4}$ and $J_{G 4}$ are the inertia of the 4 th gear pair, $J_{P 5}$ and $J_{G 5}$ are the inertia of the 5 th gear pair, $J_{S 2}$ is the inertia of the 3rd and 4th gear pair synchronizer, $J_{S 3}$ is the inertia of the 5 th gear pair synchronizer, $J_{F D 1}$ is the pinion gear inertia of the final drive gear pair, $J_{F D 2}$ is the sum inertia of differential ring gear, differential shell, planetary gear, and axis pin, $J_{D 1}$ and $J_{D 2}$ are the inertia of a planetary gear about its own rotational axis, $J_{D 3}$ and $J_{D 4}$ are the inertia of a half axle gear about its own rotational axis, $J_{s l}$ is the sum inertia of the left half axle, wheel hub, wheel rim, and brake disc, $J_{s r}$ is the sum inertia of the right half axle, wheel hub, wheel rim, and brake disc, $J_{t l}$ is the inertia of the left-front tire, $J_{t r}$ is the inertia of the right-front tire, $m$ is the vehicle mass, $k_{j}(j=1,2, \ldots, 5)$ is the meshing stiffness of gear pairs, $c_{j}(j=1,2, \ldots, 5)$ is the meshing damping of gear pairs, and $b_{j}(j=1,2, \ldots, 5)$ are the backlash of unloaded gear pairs. Other $k$ and $c$ are torsional stiffness and torsional damping, respectively.

Here, in these matrices of $\mathbf{J}, \mathbf{K}, \mathbf{C}, \boldsymbol{\theta}$, and $\mathbf{T}$, some parameters are formulated:

$$
\begin{aligned}
k_{1} & =k_{1 t} \cos ^{2}\left(\beta_{b 1}\right), \\
k_{f}= & k_{f t} \cos ^{2}\left(\beta_{b f}\right), \\
T_{g l}= & F_{x f l} r+\frac{r F_{z f} f}{2}, \\
T_{g r}= & F_{x f r} r+\frac{r F_{z f} f}{2}, \\
F_{x f l}= & \frac{\left(\sigma_{0} z_{l}+\sigma_{1} \dot{z}_{l}+\sigma_{2} v_{r l}\right) F_{z f}}{2}, \\
F_{x f r}= & \frac{\left(\sigma_{0} z_{r}+\sigma_{1} \dot{z}_{r}+\sigma_{2} v_{r r}\right) F_{z f}}{2}, \\
F_{z f}= & \frac{L_{b} m g-m x_{a} H}{L_{a}+L_{b}}, \\
F_{z r}= & \frac{L_{a} m g+m x_{a} H}{L_{a}+L_{b}},
\end{aligned}
$$




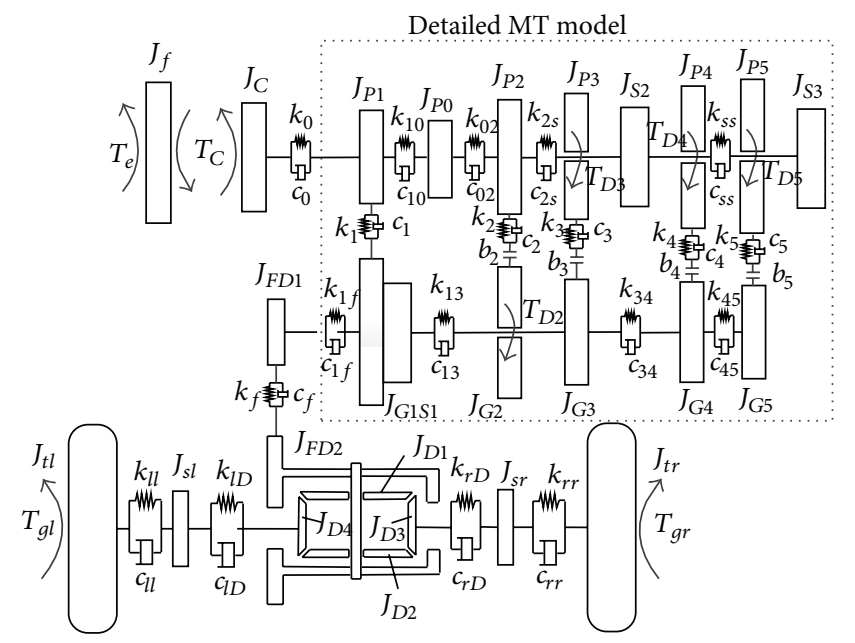

FIGURE 16: The torsional vibration model of vehicle driveline with detailed MT model for the first speed.

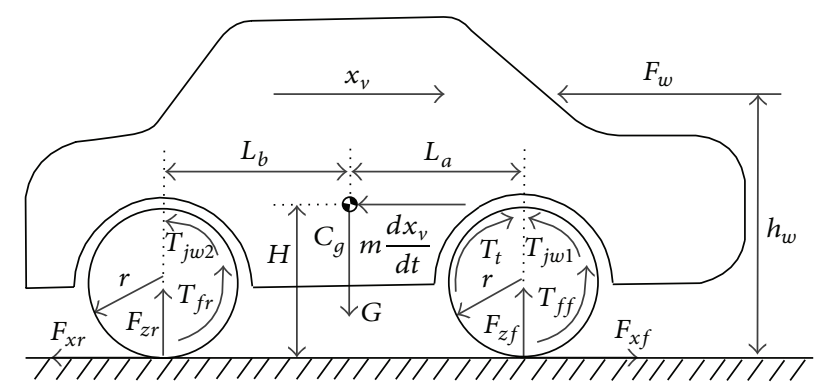

FIGURE 17: The half vehicle longitudinal motion and force analysis diagram.

$$
\begin{aligned}
& v_{r l}=\theta_{t l} r-x_{v}, \\
& v_{r r}=\theta_{t r} r-x_{v}, \\
& F_{w}=\frac{1}{2} C_{D} A \rho x_{v}^{2},
\end{aligned}
$$

where $\beta_{b 1}$ is the helical angle on base circle of the pinion gear on the 1st gear, $\beta_{b f}$ is the helical angle on base circle of the pinion gear on the final drive gear, $r$ is the tire dynamic radius, $f$ is the rolling resistance coefficient, $z_{i}(i=l, r)$ is the tire bristle average deformation in LuGre tire model, $\dot{z}_{i}(i=$ $l, r)$ is the tire bristle average deformation rate in LuGre tire model, $L_{a}$ is the distance from the mass center to the front axle, $L_{b}$ is the distance from the mass center to the rear axle, $H$ is the mass center height, $x_{a}$ is the vehicle longitudinal acceleration, $x_{v}$ is the vehicle longitudinal velocity, $C_{D}$ is the air resistance coefficient, $A$ is the vehicle frontal area, and $\rho$ is the air density.

\subsection{The Rattling Vibration Model of Unloaded Gear Pairs.}

The rattling impact is the source of rattle noise. The impact collisions through their gear backlash are transmitted to the transmission housing via shafts and bearings. The vibrations

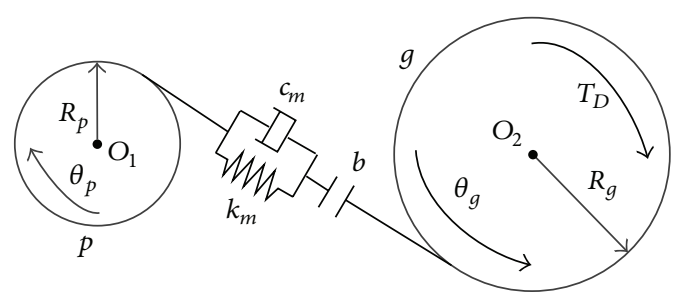

FIGURE 18: A simplified model of a rattling gear pair.

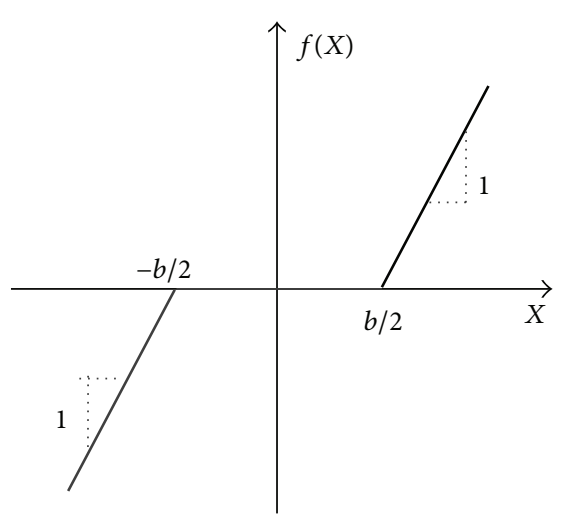

Figure 19: Backlash function.

are then converted into an audible rattle. So rattling force is the focus of dynamic study of each gear pair.

For one rattling gear pair, the mechanical model is as shown in Figure 18. Each gear is equivalent to a lumped inertia. As the motion of the pinion gear $p$, which is obtained in the baseline model, is taken as an excitation to the system, for 1st shift, pinion gears include the 2nd driving gear, the 3rd driven gear, the 4 th driven gear, and the 5 th driven gear in Figure 8. So rattling force of unloaded gear pair is deduced:

$$
\begin{aligned}
& X=\theta_{P} R_{P}-\theta_{g} R_{g}, \\
& \frac{I_{g}}{R_{g}} \ddot{X}-\frac{R_{P}}{R_{g}} I_{g} \ddot{\theta}_{p}+F m \cdot R_{g}-T_{D}=0, \\
& F m=k_{m} f(X)+c_{m} \dot{f}(X) .
\end{aligned}
$$

Here, $X$ denotes the relative displacement along the line of conjugate action of unloaded gear pairs. Therefore, each rattling gear pair is then reduced to a single degree of freedom system. $f(X)$ and $\dot{f}(X)$ are the backlash function, as shown in Figure 19, and its derivative function, respectively, which are defined as

$$
f(X)= \begin{cases}X-\frac{b}{2} & X>\frac{b}{2} \\ 0 & -\frac{b}{2}<X<\frac{b}{2} \\ X+\frac{b}{2} & X<-\frac{b}{2},\end{cases}
$$




$$
\dot{f}(X)=\left\{\begin{array}{lc}
\dot{X} & X>\frac{b}{2} \\
0 & -\frac{b}{2}<X<\frac{b}{2} \\
\dot{X} & X<-\frac{b}{2},
\end{array}\right.
$$

where $\theta_{P}$ is the driving gear $\mathrm{AD}, \theta_{g}$ is the driven gear $\mathrm{AD}$, $R_{P}$ is the base circle radius of the driving gear, $R_{g}$ is the base circle radius of the driven gear, $I_{g}$ is the inertia of the driven gear, $T_{D}$ is the drag torque applied on the driven gear, $F m$ is the rattling force, $k_{m}$ is the average meshing stiffness of the gear pair, $c_{m}$ is the average meshing damping of the gear pair, and $b$ is the gear backlash.

3.4. Simulation Method and Numerical Algorithm. As equations of the baseline vibration and the rattling vibration are derived, the driveline vibration includes highly nonlinear factors and the condition number of the system matrix, which is the ratio of its maximum to minimum eigenvalue, is very high. As MATLAB is taken as our numerical simulation tool, a "stiff" problem for ordinary differential equation (ODE) is usually difficult to solve on hand.

MATLAB provides kinds of solvers for stiff ODE, which consist of ODE15s, ODE23s, ODE23t, and ODE23tb. Among them, ODE15s is a variable order solver based on the numerical differentiation formulas. Optionally, it uses the backward differentiation formulas, and it is also known as Gear's method, which are usually less efficient. ODE23s is based on a modified Rosenbrock formula of order 2. Because it is a one-step solver, it is more efficient than ODE15s at crude tolerances and it could solve some kinds of stiff problems for which ODE15s is not effective [34, 35]. ODE23s is used for the stiff problem on hand and it is found that the efficiency is acceptable.

\section{Simulation Results Analysis}

4.1. The Driveline Vibration Analysis. In the numerical model, required parameters are from a mass production vehicle. A proper and accurate driveline model could insure a practical result. Firstly, a two-stage stiffness clutch damper (see Figure 20) is adopted in the baseline model. And the twostage stiffness clutch damper characteristics including elastic and hysteresis property, adopted in the original driveline system, are described in Figure 21 in the solid line.

According to (26), in the time domain, the vehicle velocity and the engine speed are obtained in Figures 22 and 23, respectively. From Figure 22, it is found that the vehicle moves forward slowly at the speed between $1.8 \mathrm{~m} / \mathrm{s}$ and $1.815 \mathrm{~m} / \mathrm{s}$, namely, the vehicle creeping speed. In Figure 23, the engine rotates at about $800 \mathrm{rpm}$ and the speed fluctuation amplitude is nearly $80 \mathrm{rpm}$, while the clutch hub rotates at about $800 \mathrm{rpm}$ and the speed fluctuation amplitude is about $10 \mathrm{rpm}$. Accordingly, the angular acceleration amplitude of the clutch hub in Figure 25 is much smaller than the acceleration amplitude of the engine in Figure 24. As seen, the clutch damper plays a role in attenuating the fluctuation amplitude

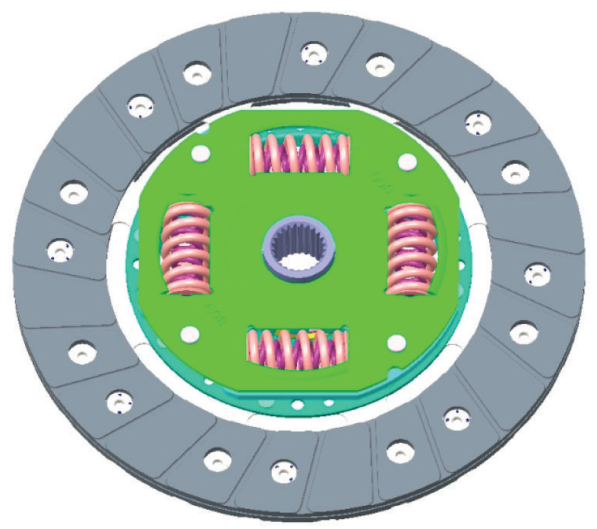

(a)

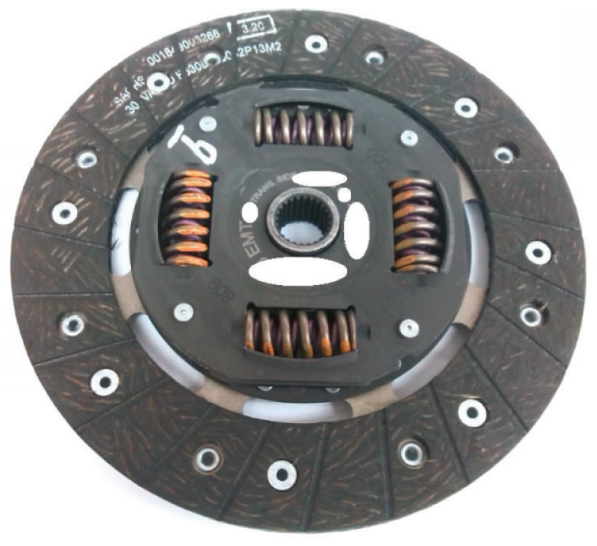

(b)

FIgure 20: A two-stage stiffness clutch damper adopted in the model: (a) 3D model, (b) physical model.

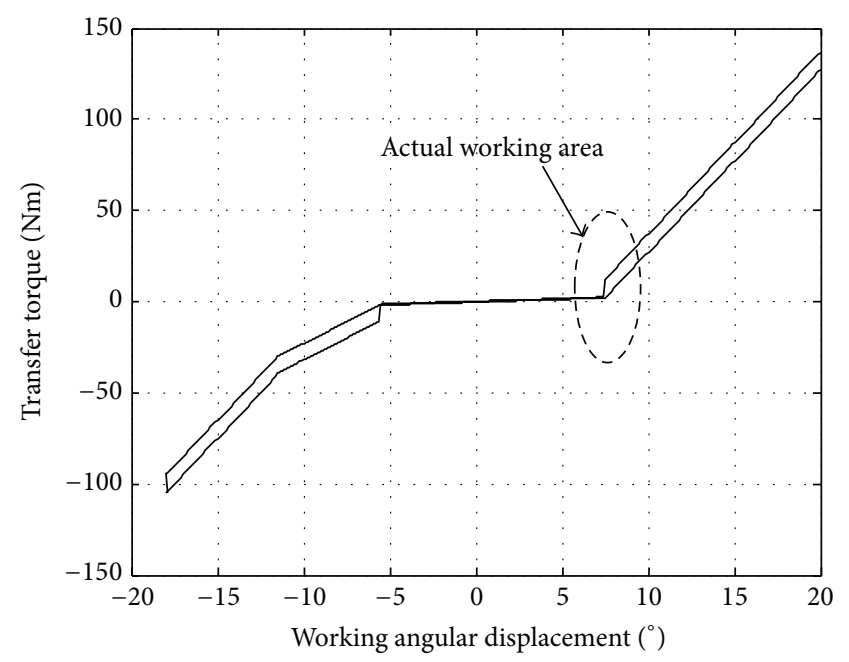

FIGURE 21: Nonlinear characteristics curve of a two-stage clutch damper.

of the engine speed in the driveline. But Figure 25 shows that the clutch hub fluctuates remarkably about the mean speed.

On this special condition, it was found that the transmission rattle was severe through the driver subjective 


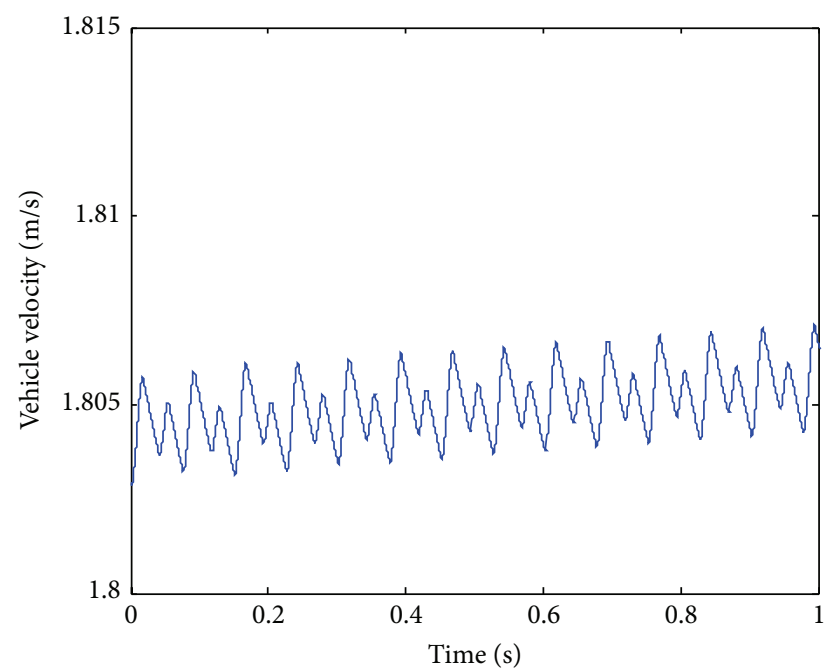

FIGURE 22: The vehicle velocity on the creeping condition.

evaluation. Now, from the simulation results in Figure 26, it is concluded that the clutch damper works at the angular displacement from $5.7^{\circ}$ to $8.6^{\circ}$ between the first and second clutch damper mass, namely, the actual working area in the dot-line ellipse in Figure 21. The clutch damper works jumping between the first-stage stiffness and the second-stage stiffness of the drive side and it excites severer driveline torsional vibration, which results in drastic fluctuation vibration of the clutch hub and transmission rattle impact noise that could be perceived by the driver or the passenger.

Besides, in the frequency domain, frequency spectrum of the engine speed (see Figure 27) shows that primary frequencies include $13.43 \mathrm{~Hz}, 26.86 \mathrm{~Hz}$, and $53.1 \mathrm{~Hz}$, which are onetime frequency, double frequency, and four-time frequency, respectively. Correspondingly, primary frequencies of the clutch hub speed (see Figure 28) include $13.43 \mathrm{~Hz}, 26.86 \mathrm{~Hz}$, and $53.1 \mathrm{~Hz}$ as well. Moreover, amplitudes of eight-time frequency $(106.2 \mathrm{~Hz})$, the twelve-time frequency $(159.3 \mathrm{~Hz})$, and other frequencies, which are compared with those amplitudes of $13.43 \mathrm{~Hz}, 26.86 \mathrm{~Hz}$, and $53.1 \mathrm{~Hz}$, are considerable. Through theoretical analysis, amplitudes of higher frequencies are smaller than those of lower frequencies. The two-stage stiffness clutch damper working between the first-stage stiffness and the second-stage stiffness could be explained for the results in Figure 28.

4.2. Rattle Force Analysis of Unloaded Gear Pairs. As explained in Section 3.3, pinion gear motions, which are obtained from the baseline vibration, are excitations to the rattling vibration. The pinion gear motions of the $2 \mathrm{nd}$, 3rd, 4 th, and 5 th gear pairs are as shown in Figure 29. Accordingly, the 2nd gear pair rattling force $F m 2$, the 3rd gear pair rattling force $F m 3$, the 4 th gear pair rattling force $F m 4$, and the 5th gear pair rattling force $F m 5$ are as shown in Figure 30.

In Figure 29, pinion gears fluctuate at the mean speed and pinion gear motions of 3rd gear pair, 4th gear pair, and 5 th gear pair are nearly consistent with each other. From Figure 30 , it is found that two-side rattling impacts happen and larger rattling force is excited in all unloaded gear pairs.

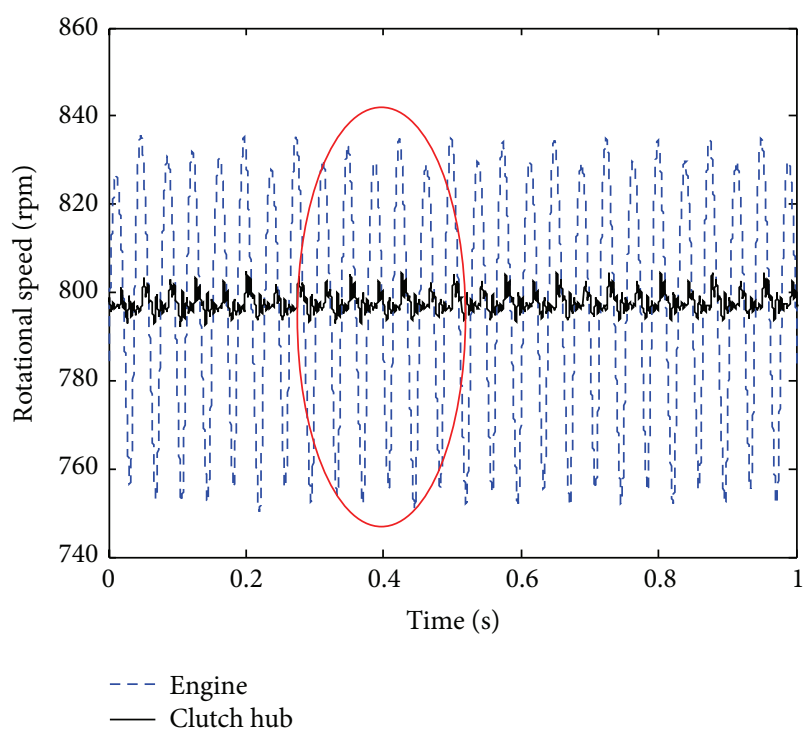

(a)

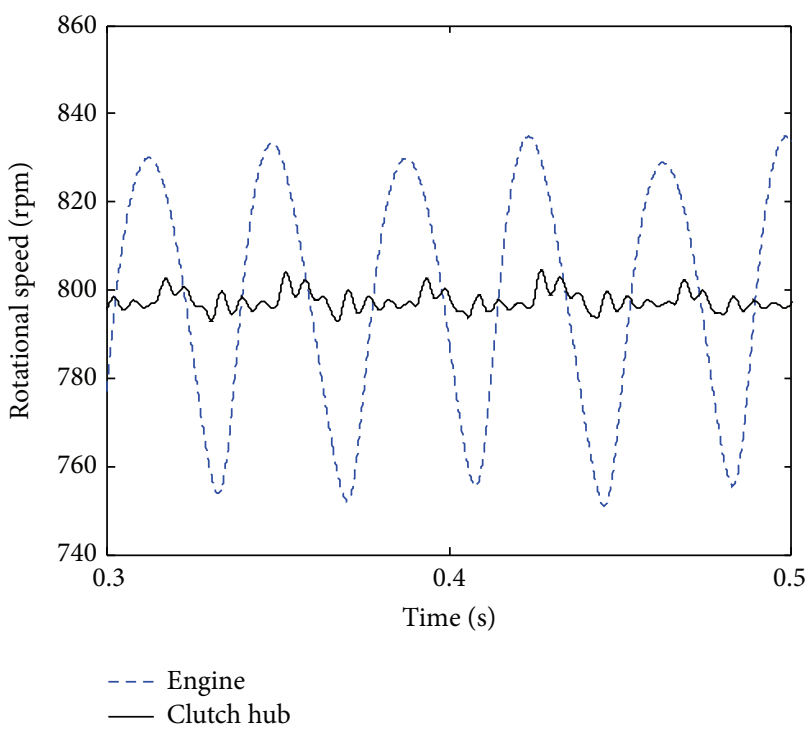

(b)

FIGURE 23: Comparison between engine speed and clutch hub speed.

Maximum amplitude of the 3rd and 4th gear pair rattling force could be nearly up to $2000 \mathrm{~N}$, while rattle force of the 2nd gear pair is about $1000 \mathrm{~N}$ and the 4th gear pair rattle force is about $500 \mathrm{~N}$. So the 3rd and 4th gear pair undergo severe rattle phenomenon. Furthermore, although pinion gear motions of 3rd gear pair, 4th gear pair, and 5th gear pair are nearly consistent, rattling forces of those three gear pairs are completely different, which proves that it is essential to establish a detailed MT model.

\section{Clutch Damper Parameters Optimization for Reducing Gear Rattle}

5.1. The Driveline Vibration Analysis after Improvement. As concluded in Section 4.1, the two-stage stiffness clutch 


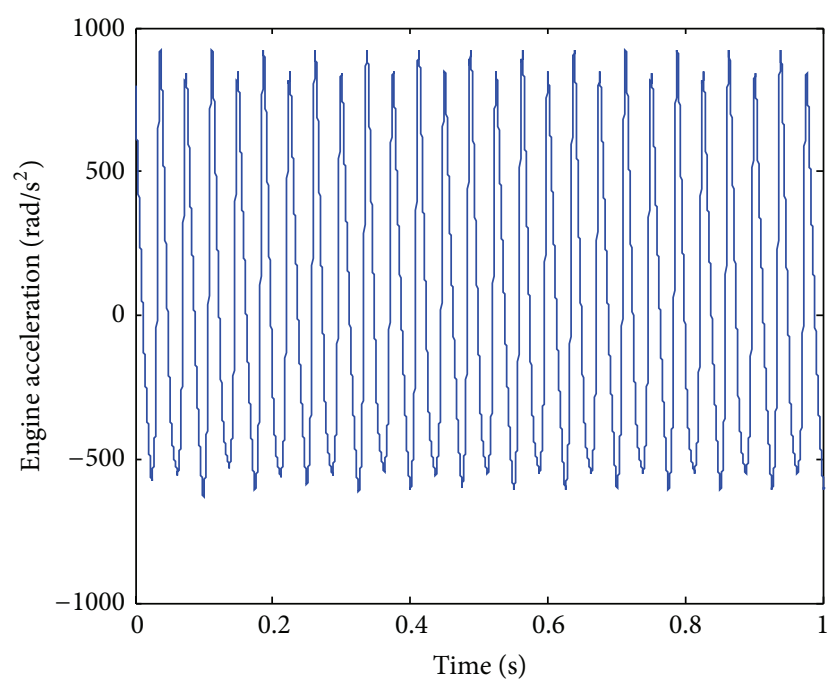

FIGURE 24: Angular acceleration of the engine.

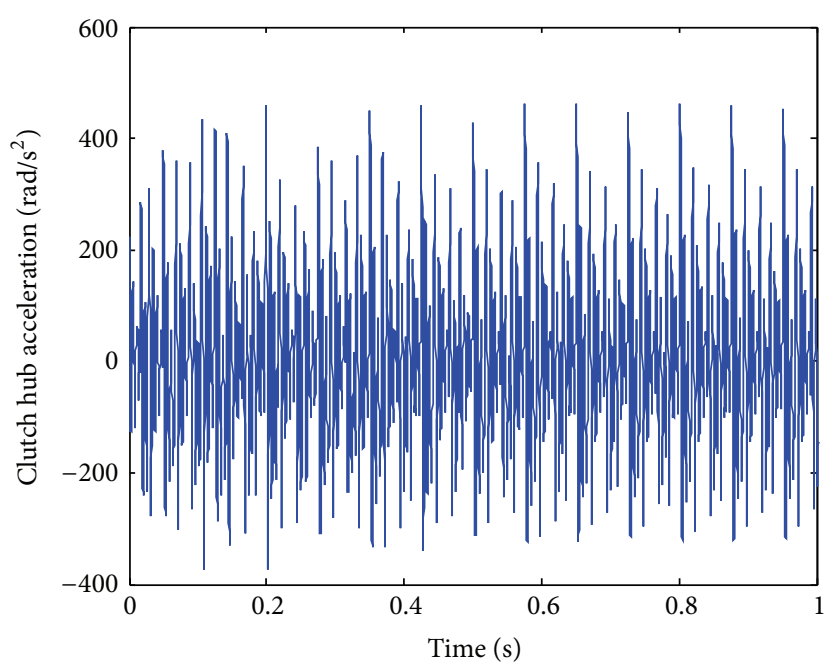

FIGURE 25: Angular acceleration of the clutch hub.

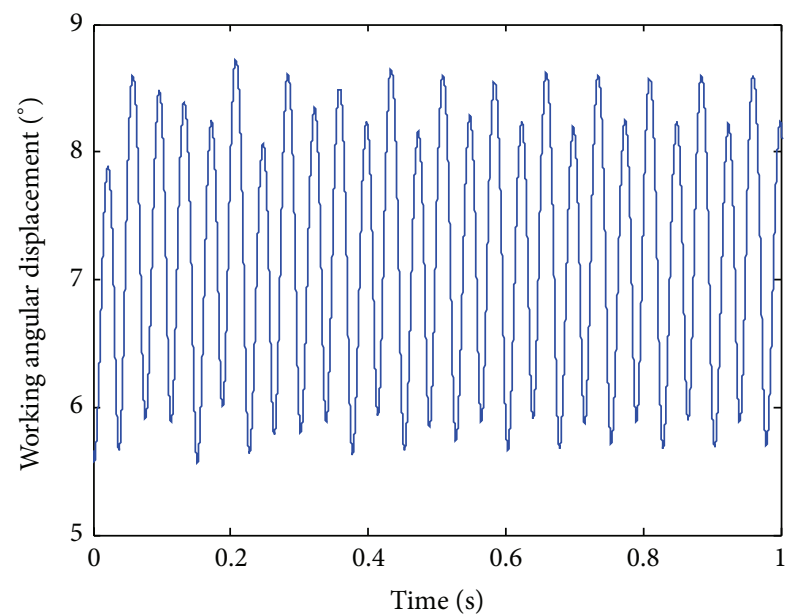

FIGURE 26: Working AD of the clutch damper.

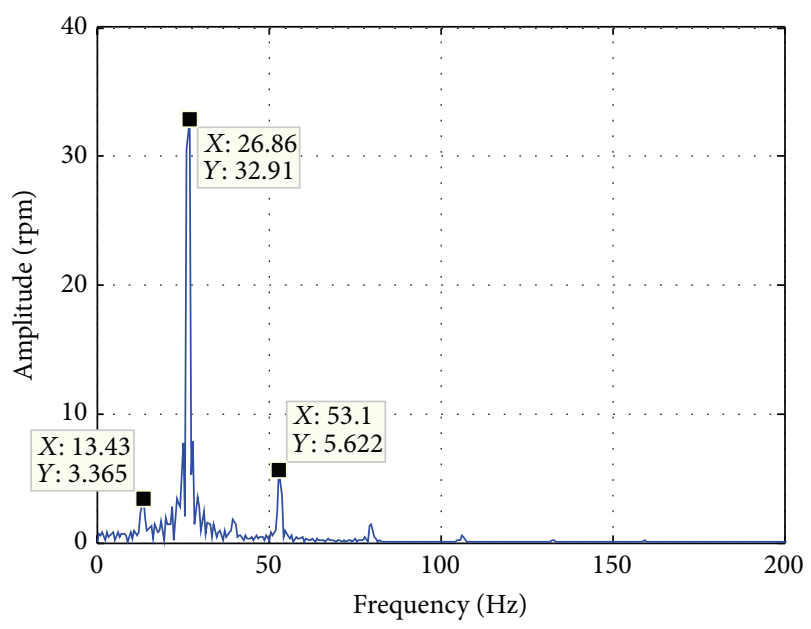

FIGURE 27: Frequency spectrum of engine speed.

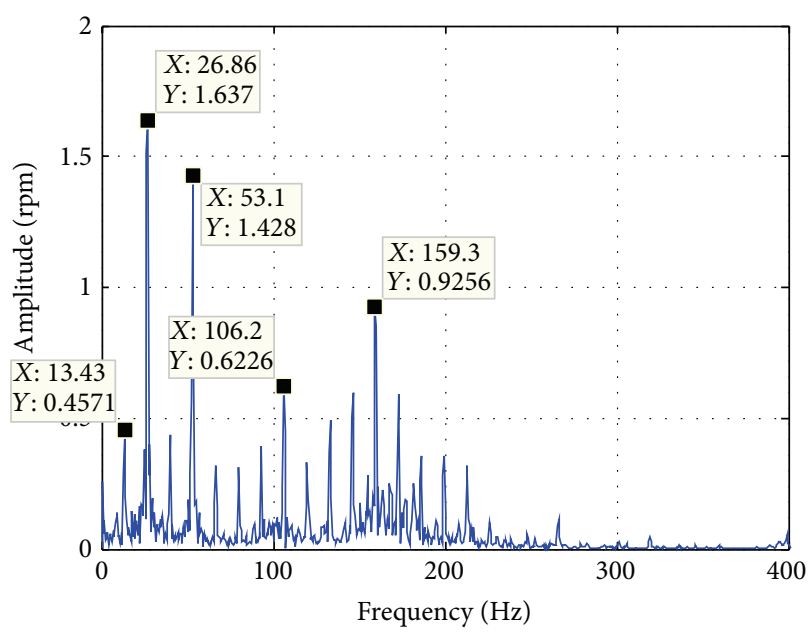

FIGURE 28: Frequency spectrum of clutch hub speed.

damper works jumping between the first- and the secondstage stiffness of the drive side, which excites severer driveline vibration and gear rattle phenomenon. So a three-stage stiffness clutch damper for adding one-stage stiffness for low load torque between the first-stage and the second-stage stiffness is proposed innovatively in Figure 31. As seen, other stage property parameters of the two-stage clutch damper are not revised except the added stage property parameters, and this three-stage clutch damper could play a good performance originally for other vehicle driving conditions except the vehicle creeping condition. Nonlinear characteristics of the three-stage clutch damper are as shown in Figure 32 in the solid line.

According to (26), in the time domain, the engine fluctuates at about $800 \mathrm{rpm}$ and speed fluctuation amplitude is nearly $80 \mathrm{rpm}$ in Figure 33, which is similar to the result in Figure 23. But it is obviously found that fluctuation degree of the clutch hub is reduced and the fluctuation amplitude is less than $10 \mathrm{rpm}$. Similarly, angular acceleration of the clutch hub in Figure 35 is much smaller than that in Figure 25, while 


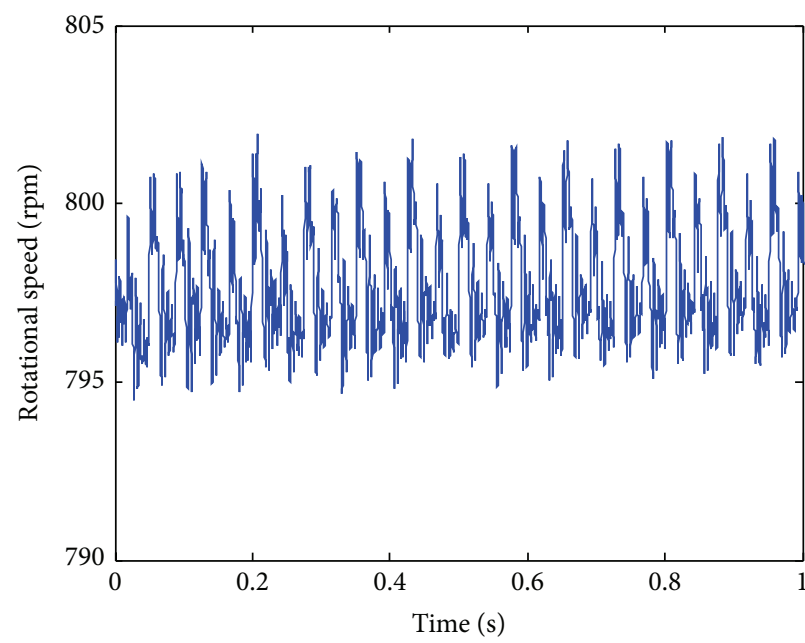

(a)

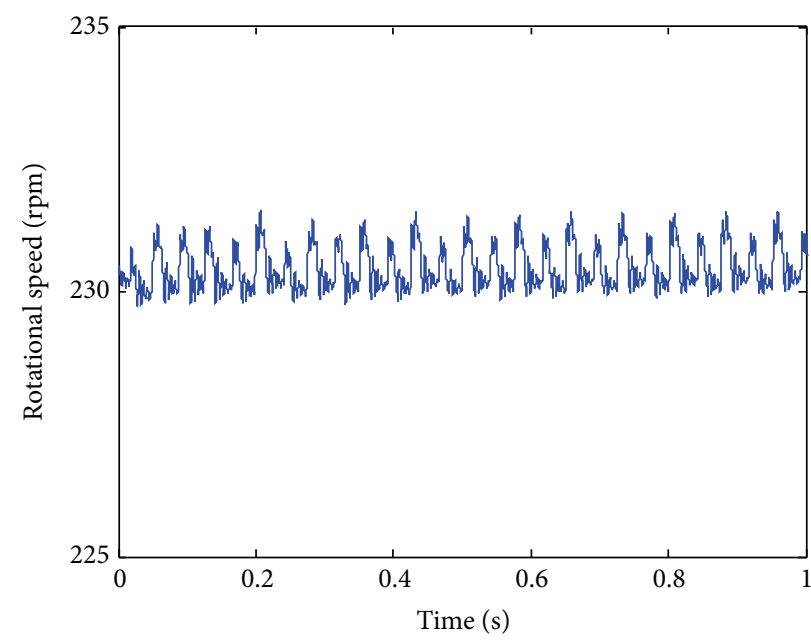

(c)

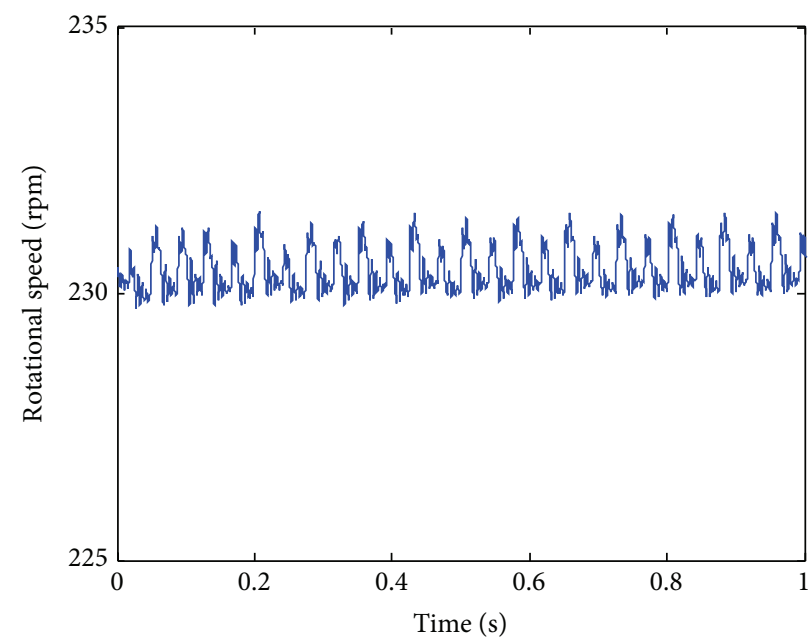

(b)

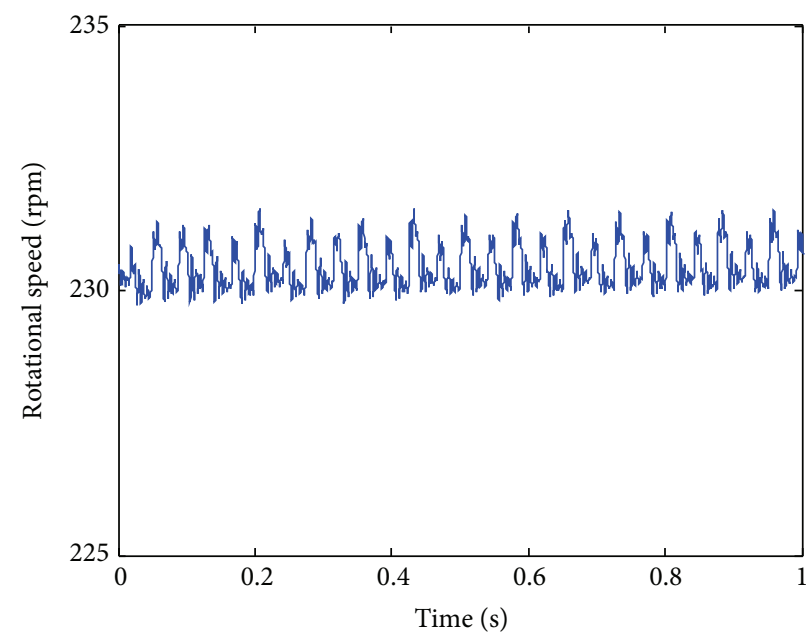

(d)

Figure 29: Pinion gear speed of all unloaded gear pairs: (a) the 2nd gear pair, (b) the 3rd gear pair, (c) the 4th gear pair, and (d) the 5th gear pair.

the angular acceleration of the engine in Figure 34 is similar to that in Figure 24.

Further analysis of the three-stage clutch damper working $\mathrm{AD}$ in Figure 36 shows that it works at the angular displacement from $5^{\circ}$ to $8^{\circ}$, namely, the actual working area in the dotline ellipse in Figure 32. Now, after adopting the three-stage clutch damper, jumping phenomenon between the first-stage stiffness and the second-stage stiffness is eliminated.

Besides, in the frequency domain, frequency spectrum of the engine speed (see Figure 37) is similar to that in Figure 27 and primary frequencies consist of $13.43 \mathrm{~Hz}, 26.86 \mathrm{~Hz}$, and $53.1 \mathrm{~Hz}$ as well. Correspondingly, primary frequencies of the clutch hub speed include $13.43 \mathrm{~Hz}, 26.86 \mathrm{~Hz}$, and $53.1 \mathrm{~Hz}$ as well in Figure 38. But in Figure 38, amplitudes of $106.2 \mathrm{~Hz}$ and $159.3 \mathrm{~Hz}$ and other frequencies in Figure 28, amplitudes of which could not be neglectful, are reduced to a much lower value. Through comprehensive analysis of those results, jumping phenomenon elimination between the first-stage stiffness and the second-stage stiffness could be explained for the result in Figure 38 after adopting the three-stage stiffness clutch damper.

5.2. Rattle Force Analysis of Unloaded Gear Pairs after Optimization. Through the baseline model, pinion gear motions of the 2nd, 3rd, 4th, and 5th gear pair after optimization are as shown in Figure 39. Compared with the result in Figure 29, speed fluctuations of all pinion gears are apparently much lower, change trends of which are the same with the clutch hub. Then, pinion gear motions are as excitations to unloaded gear pairs and rattle forces of unloaded gear pairs are calculated in Figure 40. Rattle intensities of all unloaded gear pairs are obviously improved and one-side rattle impacts are dominant in all unloaded gear pairs. Maximum rattle force of the 2nd gear pair is less than $150 \mathrm{~N}$ and rattle force of the 3 rd gear pair is less than $50 \mathrm{~N}$, while rattle force of the 4 th and 5th gear pair is similarly less than $100 \mathrm{~N}$. It is concluded that all unloaded gear pairs undergo rattle vibration, but the intensity of rattle impacts is much weaker. So MT rattle 


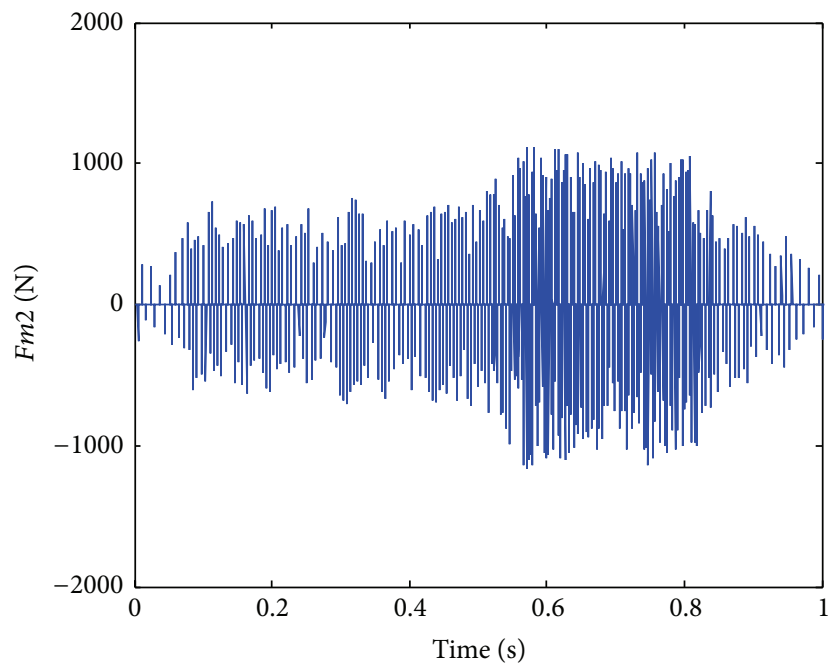

(a)

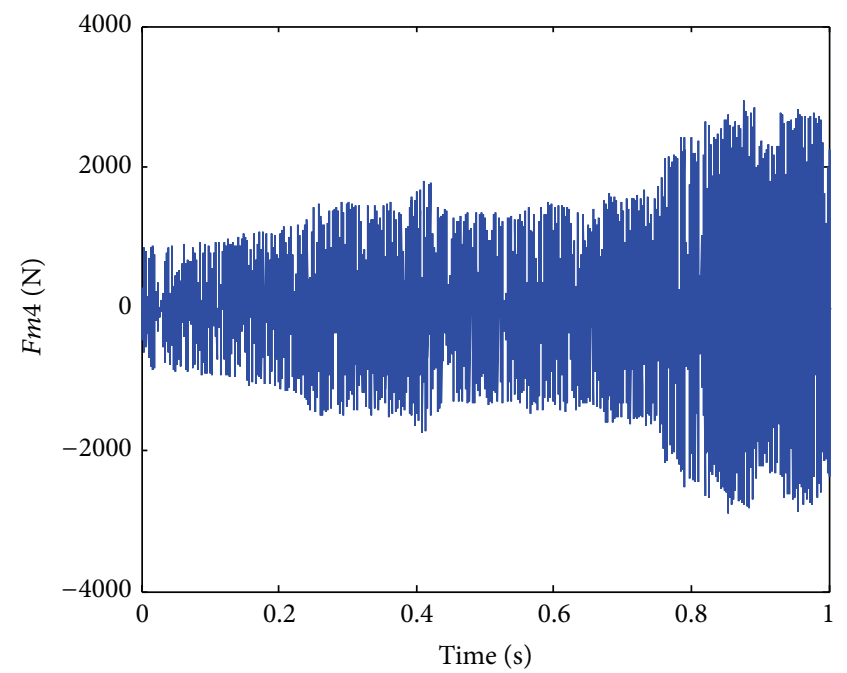

(c)

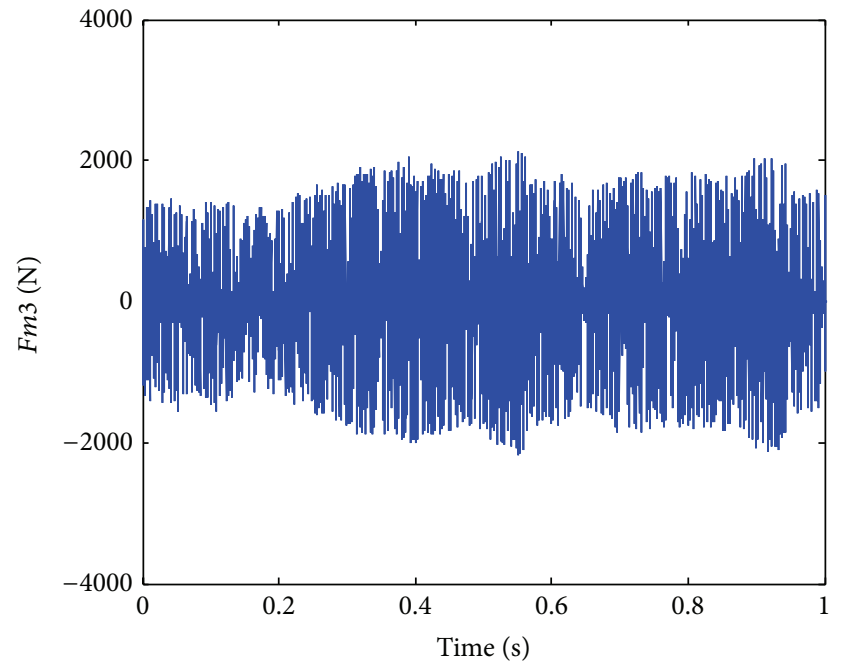

(b)

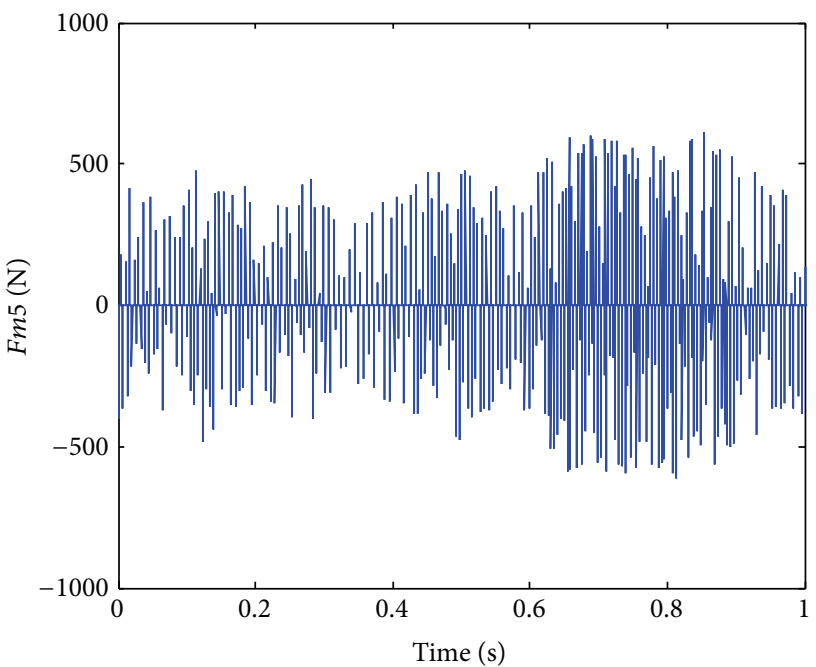

(d)

FIGURE 30: Rattle force of all unloaded gear pairs: (a) the 2nd gear pair, (b) the 3rd gear pair, (c) the 4th gear pair, and (d) the 5th gear pair.

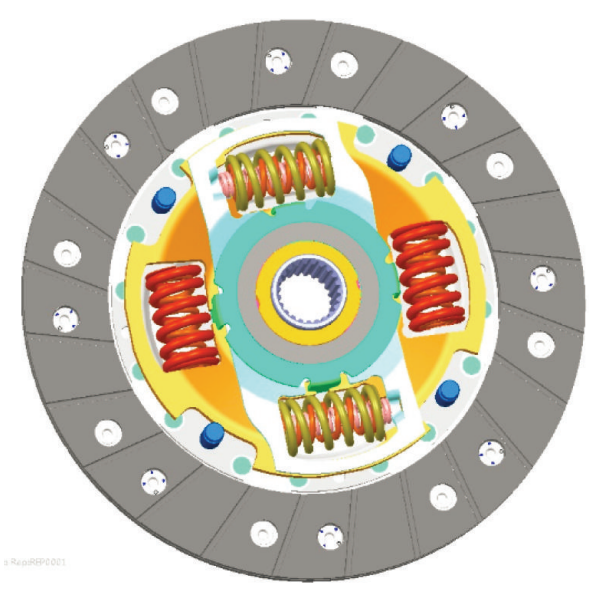

(a)

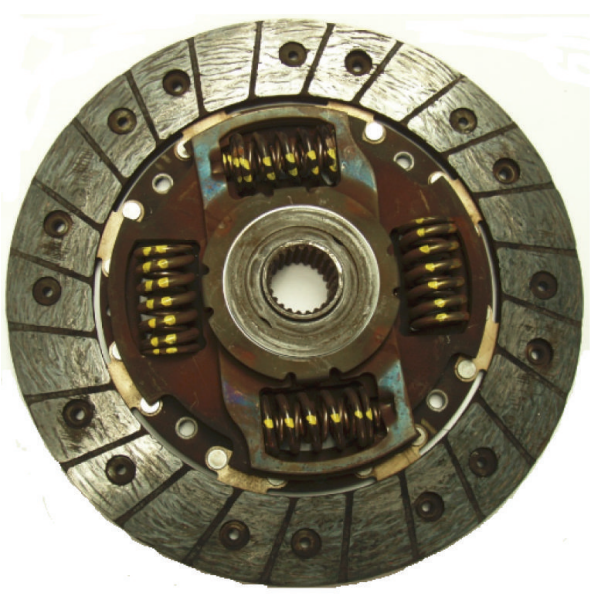

(b)

FIGURE 31: A three-stage stiffness clutch damper adopted in the model: (a) 3D model, (b) physical model. 


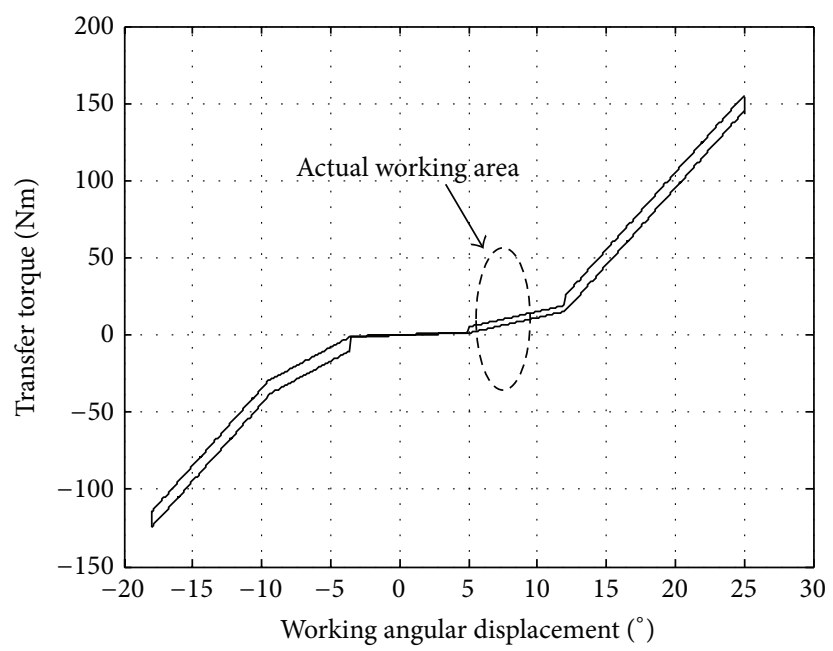

Figure 32: Nonlinear characteristics of a three-stage clutch damper.

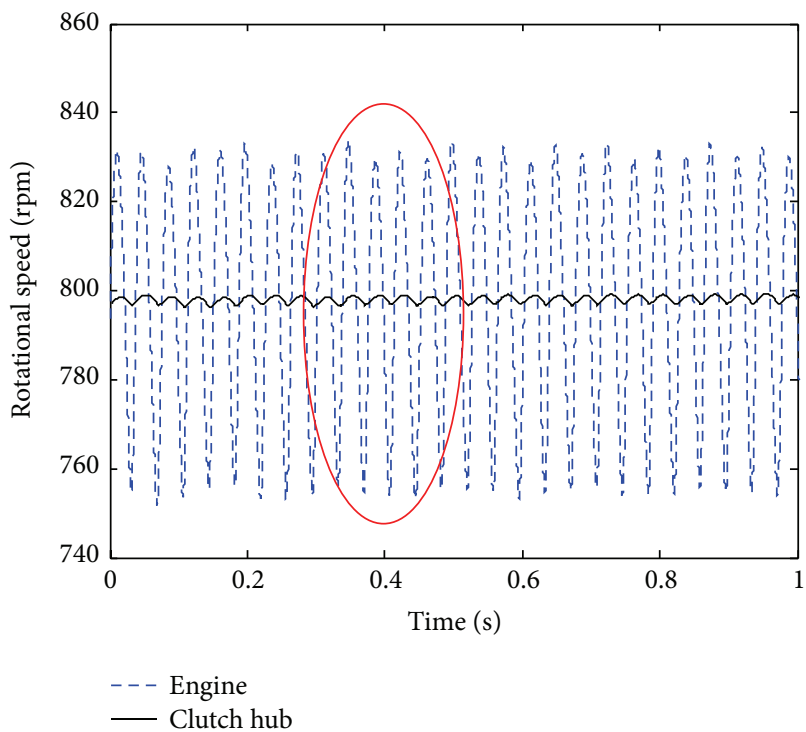

(a)

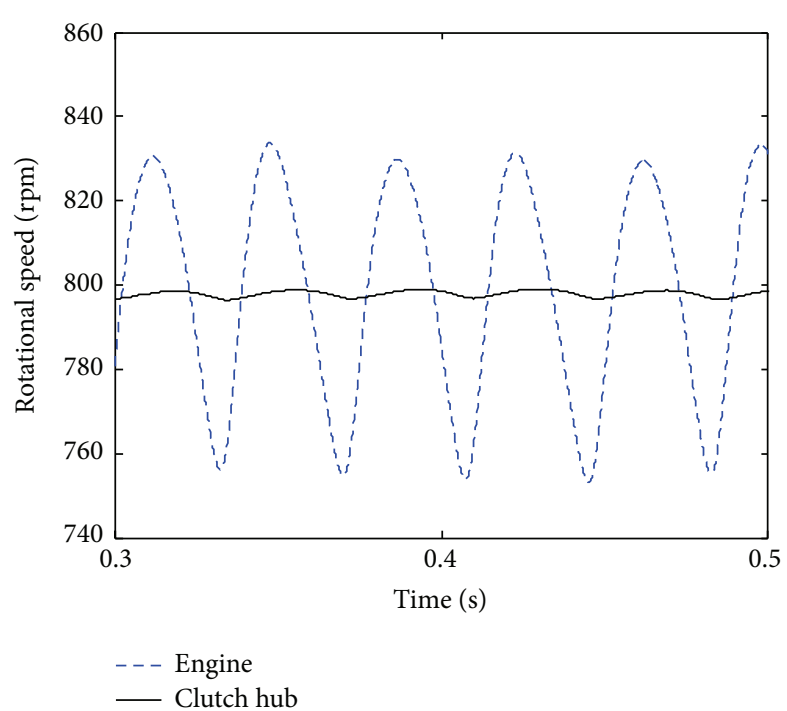

(b)

Figure 33: Comparison between engine speed and clutch hub speed.

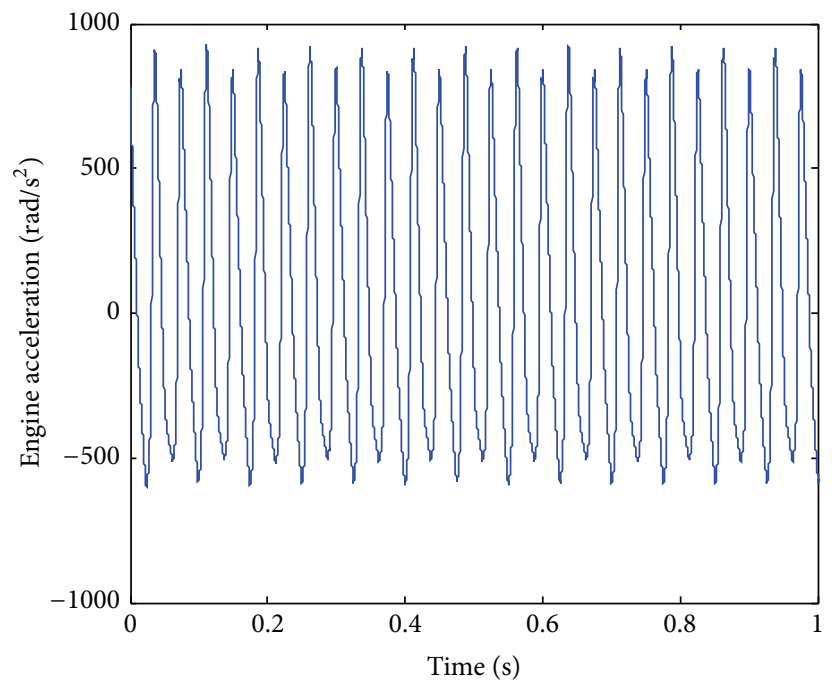

FIgURE 34: Angular acceleration of the engine. 


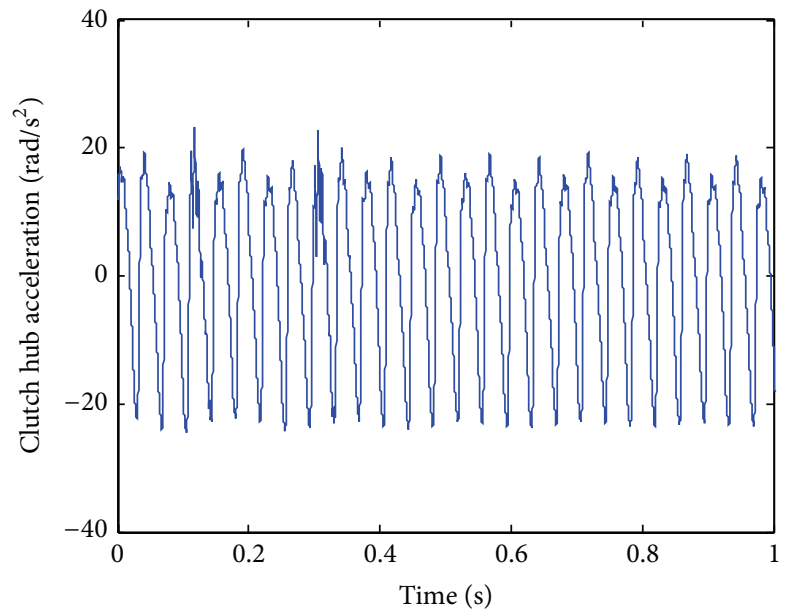

FIgURE 35: Angular acceleration of the clutch hub.

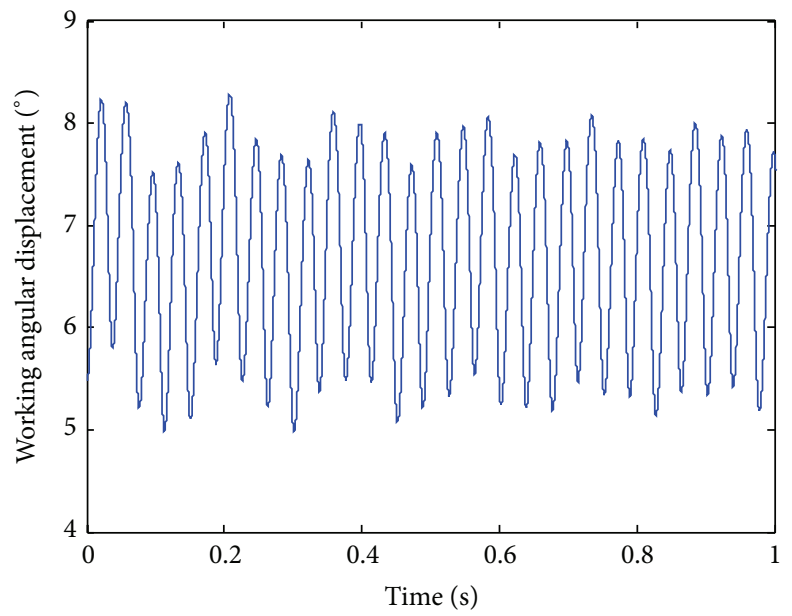

FIGURE 36: Working AD of the three-stage stiffness clutch damper.

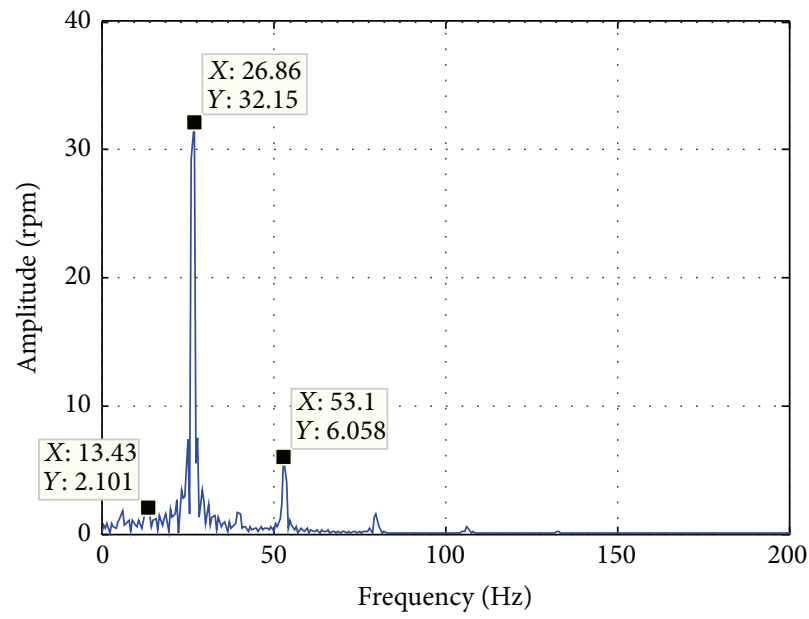

FIGURE 37: Frequency spectrum of engine speed. 


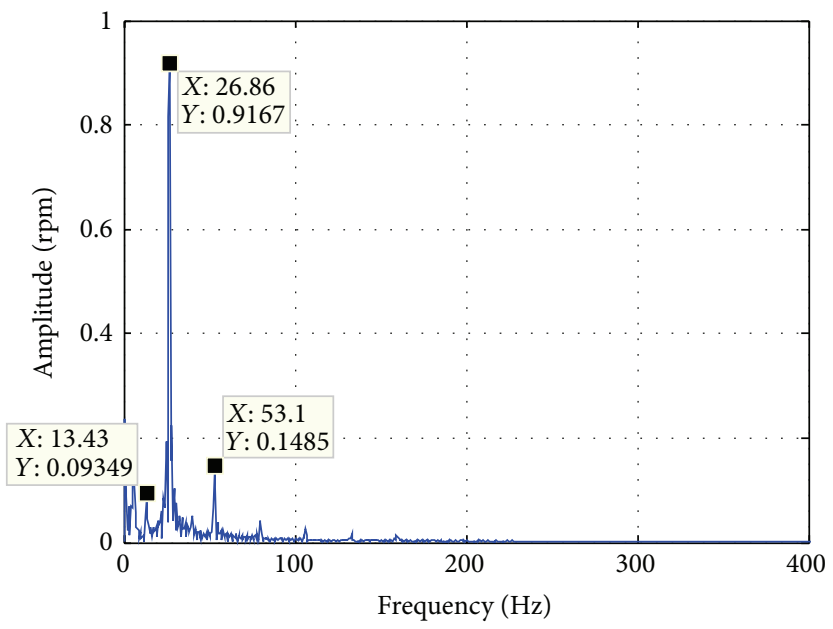

FigURE 38: Frequency spectrum of clutch hub speed.

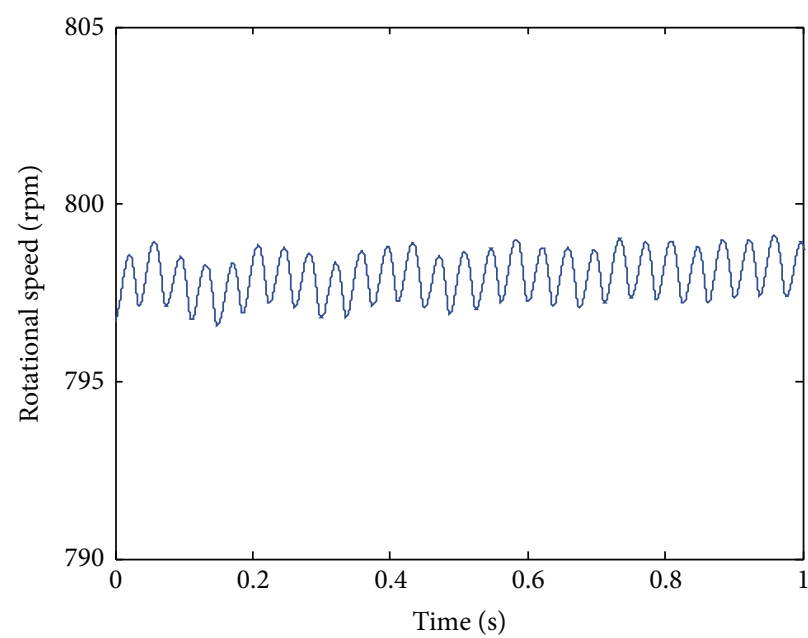

(a)

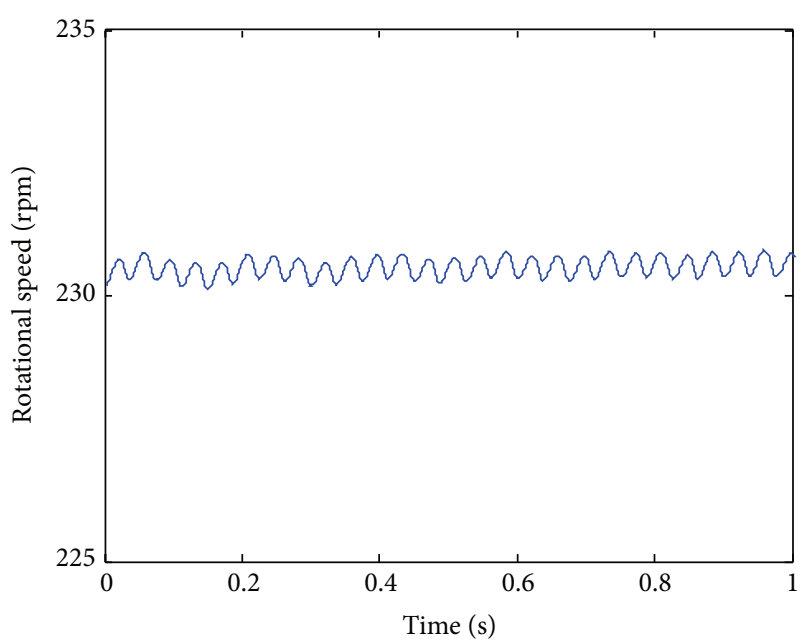

(c)

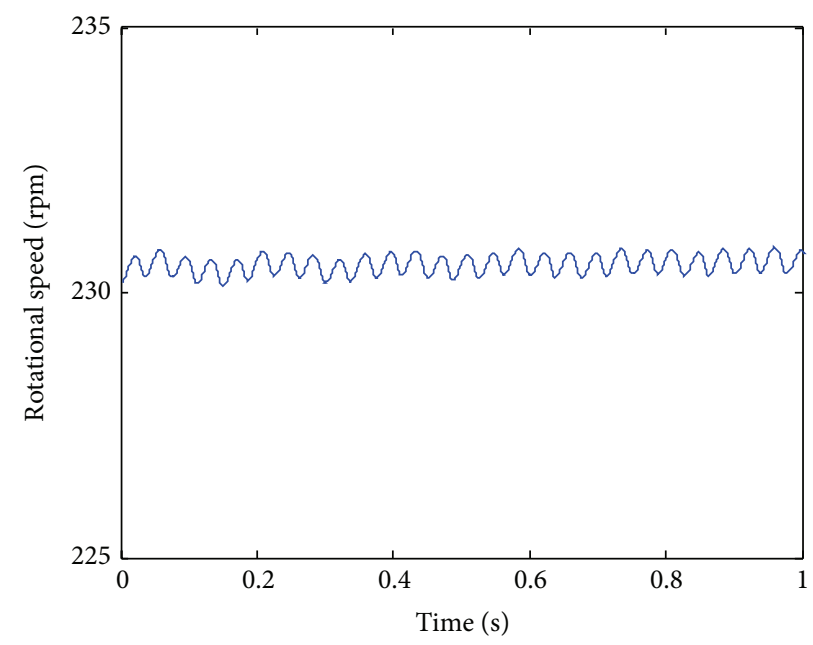

(b)

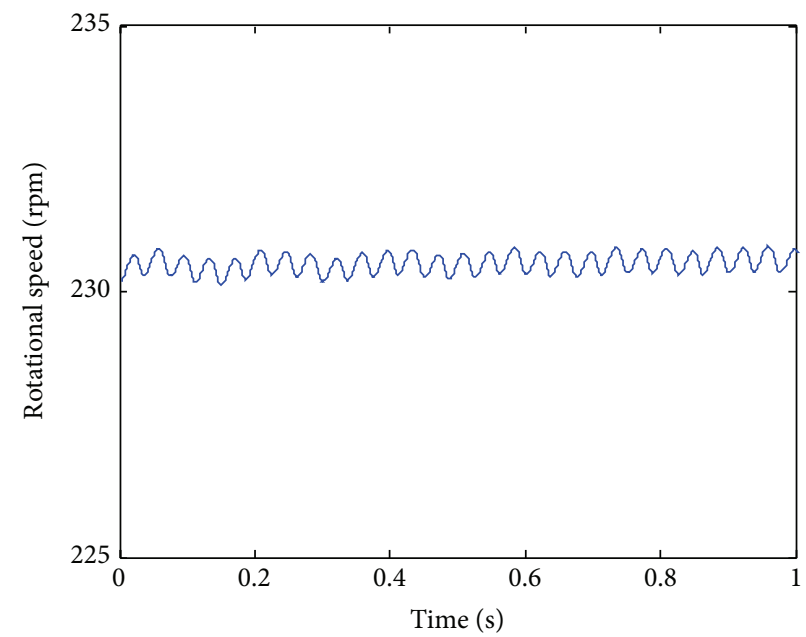

(d)

Figure 39: Pinion gear speed of unloaded gear pairs after optimization: (a) the 2nd gear pair, (b) the 3rd gear pair, (c) the 4th gear pair, and (d) the 5th gear pair. 


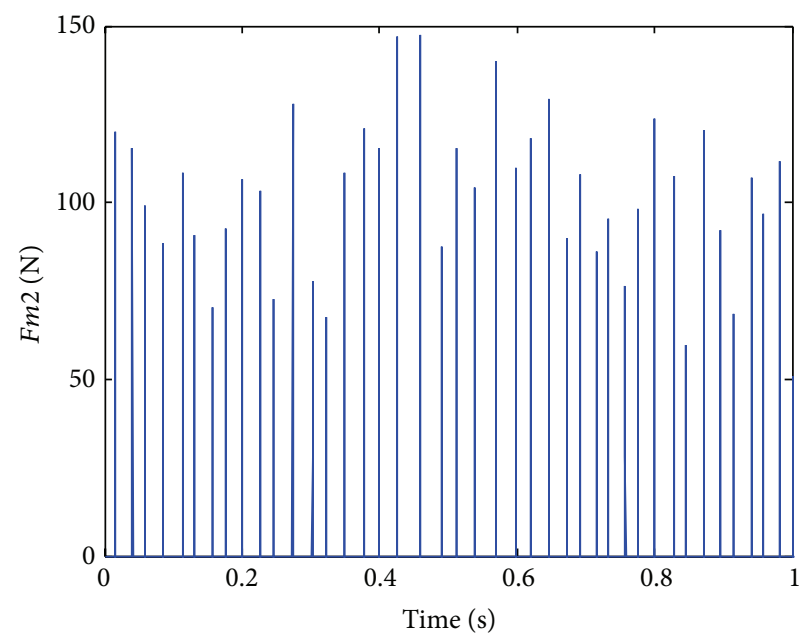

(a)

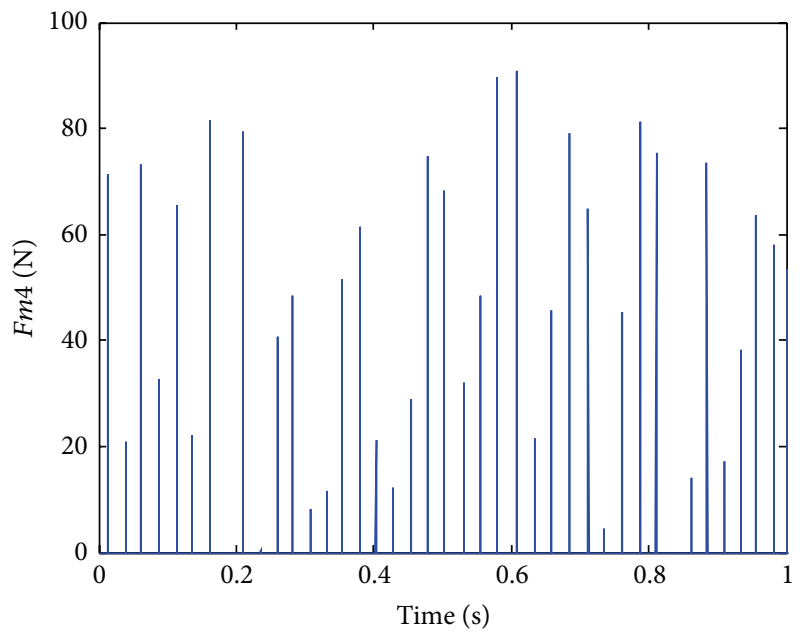

(c)

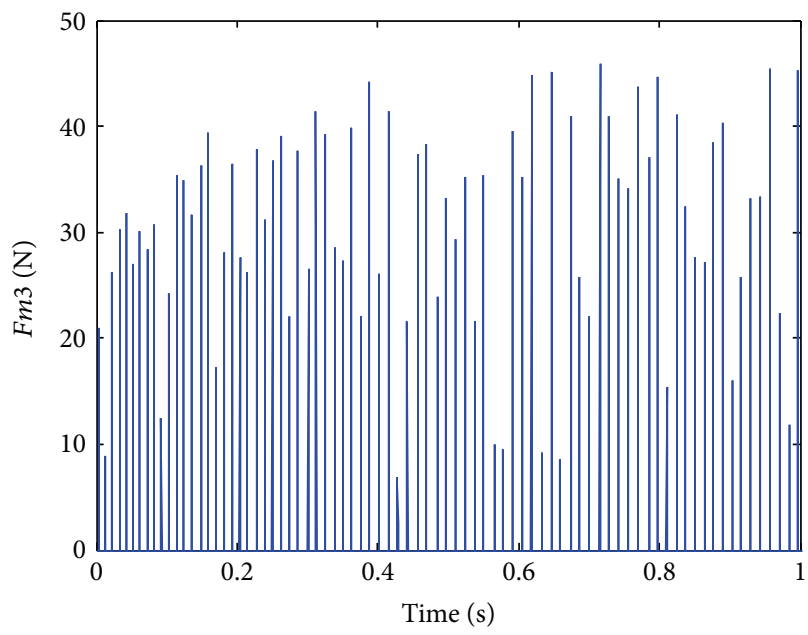

(b)

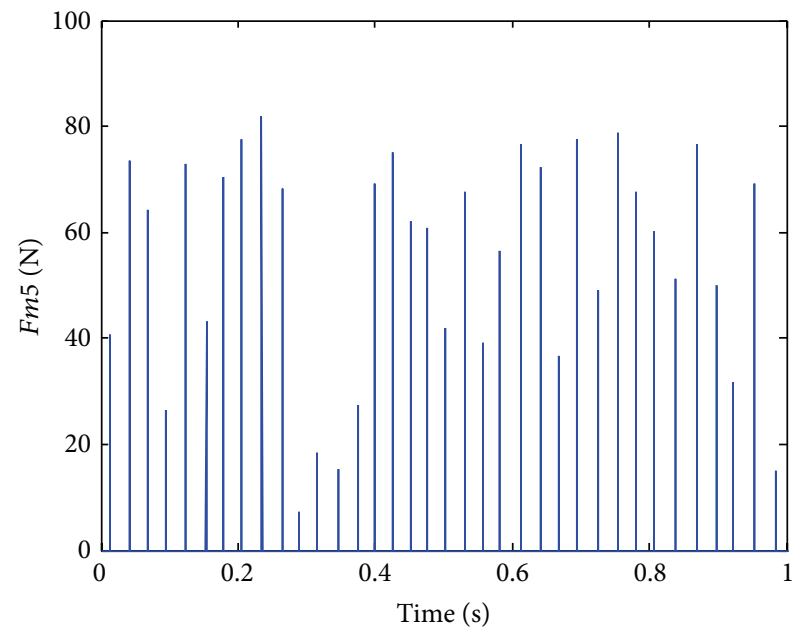

(d)

FIGURE 40: Rattle force of unloaded gear pairs after optimization: (a) the 2nd gear pair, (b) the 3rd gear pair, (c) the 4th gear pair, and (d) the 5 th gear pair.

phenomenon (or rattle force) is improved after adopting the three-stage stiffness clutch damper on the vehicle creeping condition.

\section{Conclusions}

Based on the branched model, including quasi-transient engine model, multistage clutch damper model, detailed MT model, differential model, and LuGre tire model, and considering time-varying stiffness of the 1st speed gear pair and final drive gear pair, 19-DOF model of the baseline vibration is established on the vehicle creeping condition. The rattling vibration is then obtained as the baseline vibration is as an excitation. The baseline vibration and the rattling vibration reproduce a comprehensive study of the driveline system and MT rattle phenomenon. It is concluded that

(1) on the creeping condition, the two-stage stiffness clutch damper tends to work jumping between the first- and second-stage stiffness and it causes severer driveline vibration and disturbing rattle noise perceived by passengers. Larger rattling force of two-side impact is excited in all unloaded gear pairs. Maximum rattle force of the 3rd and 4th gear pair is up to about $2000 \mathrm{~N}$, while rattle force of the 2 nd gear pair is about $1000 \mathrm{~N}$ and rattle force of the 4th gear pair is nearly $500 \mathrm{~N}$;

(2) a three-stage stiffness clutch damper is adopted and it could obviously improve the driveline vibration and MT rattle phenomenon on the vehicle creeping condition. One-side impacts are dominant in all unloaded gear pairs. Maximum rattle force of the 4 th and 5th gear pair is less than $100 \mathrm{~N}$, while rattle force of the 2nd gear pair is smaller than $150 \mathrm{~N}$ and rattle force of the 3rd gear pair is less than $500 \mathrm{~N}$;

(3) achievements of numerical simulation developed in this research could be utilized for the design of driveline system and practical strategies for solving MT rattle phenomenon. Currently, all results are 
mainly obtained from numerical modeling and simulation and they are indispensable to be validated with further experimental results.

\section{Conflict of Interests}

The authors declare that there is no conflict of interests regarding the publication of this paper.

\section{Acknowledgment}

The research leading to these results has received funding from the National Natural Science Foundation of China (Grant no. 51175379).

\section{References}

[1] K. Nakamura, "Tooth separations and abnormal noise on power-transmission gears," Bulletin of JSME, vol. 10, no. 41, pp. 846-854, 1967.

[2] R. J. Comparin and R. Singh, "Non-linear frequency response characteristics of an impact pair," Journal of Sound and Vibration, vol. 134, no. 2, pp. 259-290, 1989.

[3] A. Kahraman and R. Singh, "Non-linear dynamics of a spur gear pair," Journal of Sound and Vibration, vol. 142, no. 1, pp. 49-75, 1990.

[4] M. Bozca, "Torsional vibration model based optimization of gearbox geometric design parameters to reduce rattle noise in an automotive transmission," Mechanism and Machine Theory, vol. 45, no. 11, pp. 1583-1598, 2010.

[5] M. Bozca and P. Fietkau, "Empirical model based optimization of gearbox geometric design parameters to reduce rattle noise in an automotive transmission," Mechanism \& Machine Theory, vol. 45, no. 11, pp. 1599-1612, 2010.

[6] M. Y. Wang, W. Zhao, and R. Manoj, "Numerical modelling and analysis of automotive transmission rattle," Journal of Vibration and Control, vol. 8, no. 7, pp. 921-943, 2002.

[7] G. Wu and W. Luan, "The impact of gear meshing nonlinearities on the vehicle launch shudder," SAE Technical Paper, 2015.

[8] D. Robinette, R. S. Beikmann, P. Piorkowski et al., "Characterizing the onset of manual transmission gear rattle part II: analytical results," SAE Technical Paper, 2009.

[9] D. Robinette, R. S. Beikmann, P. Piorkowski, and M. Powell, "Characterizing the onset of manual transmission gear rattle part I: experimental results," SAE Technical Paper, 2009.

[10] M. De La Cruz, S. Theodossiades, and H. Rahnejat, "An investigation of manual transmission drive rattle," Proceedings of the Institution of Mechanical Engineers, Part K, vol. 224, no. 2, pp. 167-181, 2010.

[11] P. Fietkau and B. Bertsche, "Influence of tribological and geometrical parameters on lubrication conditions and noise of gear transmissions," Mechanism and Machine Theory, vol. 69, pp. 303-320, 2013.

[12] S. Theodossiades, O. Tangasawi, and H. Rahnejat, "Gear teeth impacts in hydrodynamic conjunctions promoting idle gear rattle," Noise \& Vibration Worldwide, vol. 303, pp. 632-658, 2007.

[13] O. Tangasawi, S. Theodossiades, and H. Rahnejat, "Lightly loaded lubricated impacts: idle gear rattle," Journal of Sound \& Vibration, vol. 308, no. 3-5, pp. 418-430, 2007.
[14] A. R. Crowther, C. Halse, and Z. Zhang, "Nonlinear responses in loaded driveline rattle," SAE Technical Paper, 2009.

[15] R. Bhagate, A. Badkas, and K. Mohan, "Driveline torsional analysis and parametric optimization for reducing driveline rattle," SAE Technical Paper, 2015.

[16] P. Couderc, J. Callenaere, J. Der Hagopian et al., "Vehicle driveline dynamic behaviour: experimentation and simulation," Journal of Sound and Vibration, vol. 218, no. 1, pp. 133-157, 1998.

[17] P. Bellomo, N. De Vito, C. H. Lang, and L. Scamardi, "In depth study of vehicle powertrains to identify causes of loose components rattle in transmissions," SAE Technical Paper 200201-0702, 2002.

[18] A. Forcelli, C. Grasso, and T. Pappalardo, "The transmission gear rattle noise: parametric sensitivity study," SAE Technical Paper 2004-01-1225, 2004.

[19] M. Barthod, B. Hayne, J.-L. Tébec, and J.-C. Pin, "Experimental study of gear rattle excited by a multi-harmonic excitation," Applied Acoustics, vol. 68, no. 9, pp. 1003-1025, 2007.

[20] A. R. Crowther and M. K. Rozyn, "Design and analysis of a gear rattle test rig," SAE International Journal of Passenger CarsMechanical Systems, vol. 2, no. 1, pp. 1431-1439, 2009.

[21] A. Baumann and B. Bertsche, "Experimental study on transmission rattle noise behaviour with particular regard to lubricating oil," Journal of Sound \& Vibration, vol. 341, pp. 195-205, 2015.

[22] R. Brancati, E. Rocca, and S. Savino, "A gear rattle metric based on the wavelet multi-resolution analysis: experimental investigation," Mechanical Systems and Signal Processing, vol. 50-51, pp. 161-173, 2015.

[23] K. Steinel, "Clutch tuning to optimize noise and vibration behavior in trucks and buses," SAE Technical Paper 2000-013292, 2000.

[24] J. S. Prasad, N. C. Damodar, and T. S. Naidu, "Clutch hysteresis maximization for elimination of gear rattle in a passenger bus," SAE Technical Paper 2013-26-0100, 2013.

[25] X. Xu, W. Fang, F. Ge, X. Chen, J. Wang, and H. Zhou, “The development and application of a novel clutch torsional damper with three-stage stiffness," Automotive Engineering, vol. 35, no. 11, pp. 1011-1022, 2013.

[26] J.-Y. Yoon and R. Singh, "Effect of the multi-staged clutch damper characteristics on the transmission gear rattle under two engine conditions," Proceedings of the Institution of Mechanical Engineers, Part D: Journal of Automobile Engineering, vol. 227, no. 9, pp. 1273-1294, 2013.

[27] S. Jadhav, "Powertrain NVH analysis including clutch and gear dynamics," SAE Technical Paper 2014-01-1680, 2014.

[28] C. D. Rakopoulos, D. T. Hountalas, A. P. Koutroubousis, and T. Zannis, "Application and evaluation of a detailed friction model on a DI diesel engine with extremely high peak combustion pressures," SAE Technical Paper 2002-01-0068, 2002.

[29] A. Palmgren, Ball and Roller Bearing Engineering, SKF Industries, Philadelphia, Pa, USA, 1959.

[30] C. Changenet, X. Oviedo-Marlot, and P. Velex, "Power loss predictions in geared transmissions using thermal networksapplications to a six-speed manual gearbox," Journal of Mechanical Design, vol. 128, no. 3, pp. 618-625, 2006.

[31] C. Canudas-de-Wit, P. Tsiotras, E. Velenis, M. Basset, and G. Gissinger, "Dynamic friction models for road/tire longitudinal interaction," Vehicle System Dynamics, vol. 39, no. 3, pp. 189226, 2003.

[32] V. Simon, "Load and stress distributions in spur and helical gears," Journal of Mechanical Design, vol. 110, no. 2, pp. 197-202, 1988. 
[33] R. W. Cornell, "Compliance and stress sensitivity of spur gear teeth," Journal of Mechanical Design, vol. 103, no. 2, pp. 447-459, 1981.

[34] L. F. Shampine and M. W. Reichelt, "The MATLAB ODE suite," SIAM Journal on Scientific Computing, vol. 18, no. 1, pp. 1-22, 1997.

[35] R. Ashino, M. Nagase, and R. Vaillancourt, "Behind and beyond the Matlab ODE suite," Computers \& Mathematics with Applications, vol. 40, no. 4-5, pp. 491-512, 2000. 


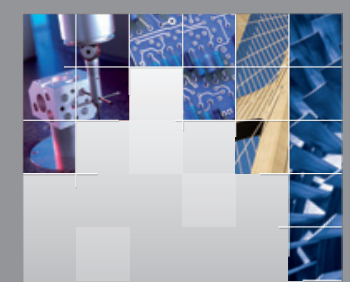

\section{Enfincering}
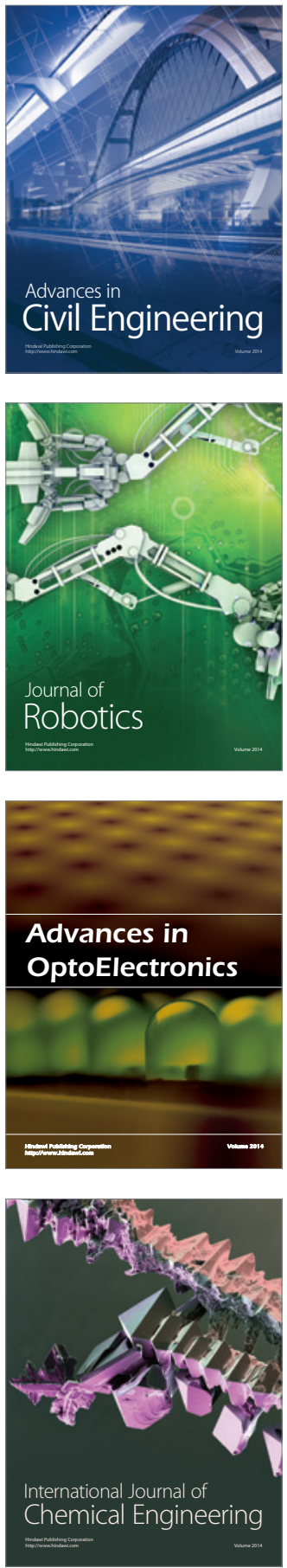

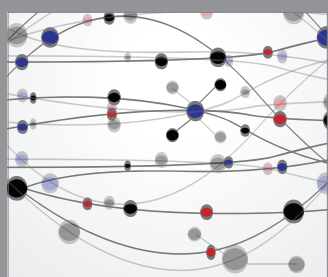

The Scientific World Journal

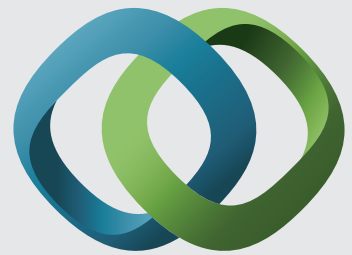

\section{Hindawi}

Submit your manuscripts at

http://www.hindawi.com
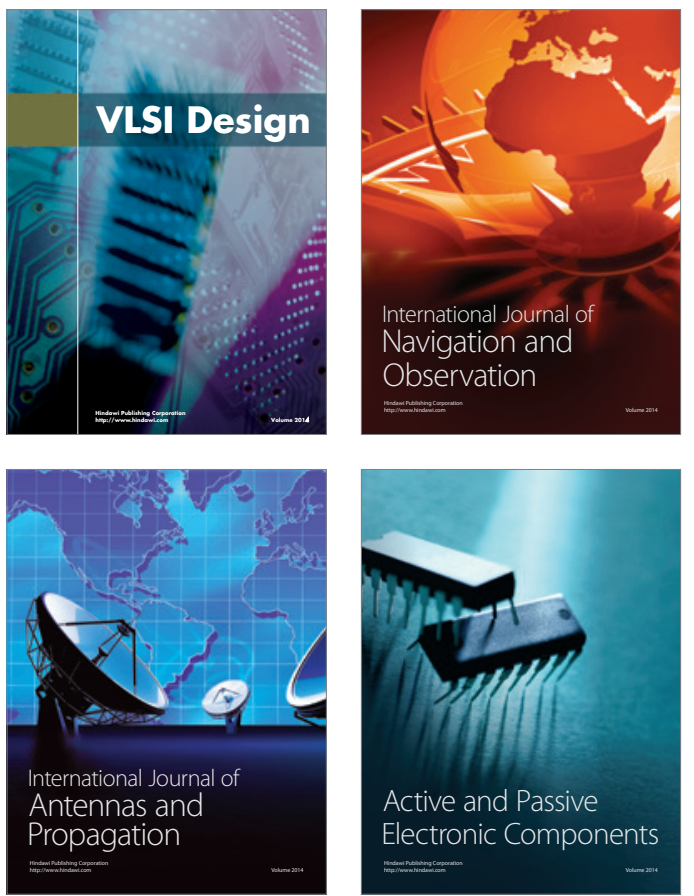
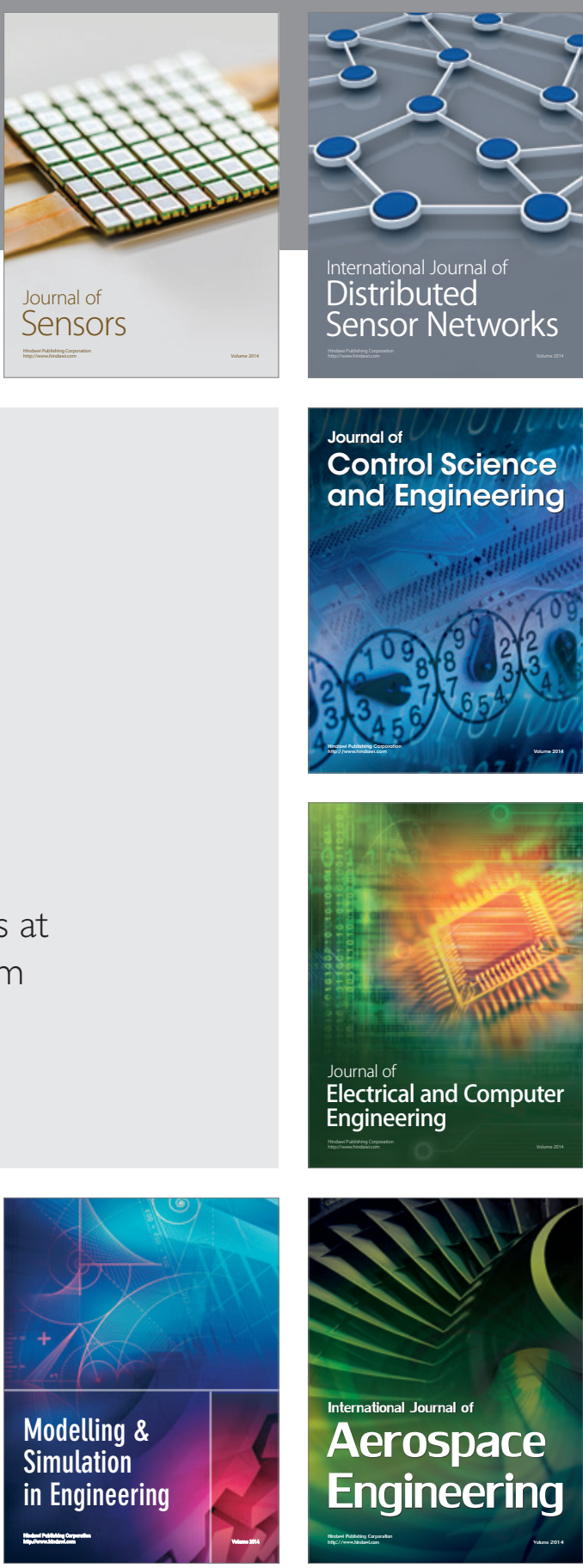

International Journal of

Distributed

Sensor Networks

Journal of

Control Science

and Engineering
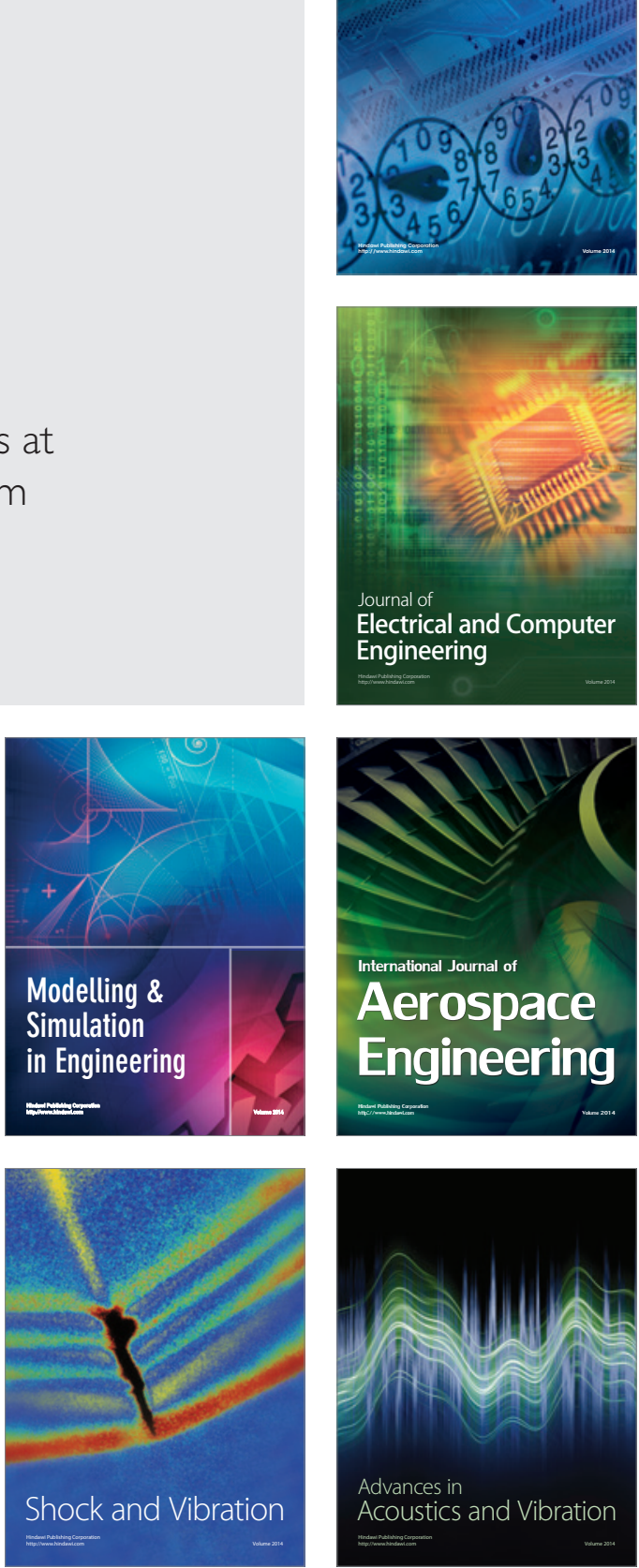